\title{
Zebrafish as an animal model to study ion homeostasis
}

\author{
Pung-Pung Hwang • Ming-Yi Chou
}

Received: 30 January 2013 /Revised: 11 March 2013 /Accepted: 12 March 2013 /Published online: 9 April 2013

(C) The Author(s) 2013. This article is published with open access at Springerlink.com

\begin{abstract}
Zebrafish (Danio rerio) possesses several advantages as an experimental organism, including the applicability of molecular tools, ease of in vivo cellular observation and functional analysis, and rapid embryonic development, making it an emerging model for the study of integrative and regulatory physiology and, in particular, the epithelial transport associated with body fluid ionic homeostasis. Zebrafish inhabits a hypotonic freshwater environment, and as such, the gills (or the skin, during embryonic stages) assume the role of the kidney in body fluid ionic homeostasis. Four types of ionocyte expressing distinct sets of transporters have been identified in these organs: $\mathrm{H}^{+}$-ATPase-rich, $\mathrm{Na}^{+}$$\mathrm{K}^{+}$-ATPase-rich, $\mathrm{Na}^{+}-\mathrm{Cl}^{-}$cotransporter-expressing and $\mathrm{K}^{+}$secreting cells; these ionocytes perform transepithelial $\mathrm{H}^{+}$ secretion $/ \mathrm{Na}^{+}$uptake/ $\mathrm{NH}_{4}{ }^{+}$excretion, $\mathrm{Ca}^{2+}$ uptake, $\mathrm{Na}^{+} / \mathrm{Cl}^{-}$ uptake, and $\mathrm{K}^{+}$secretion, respectively. Zebrafish ionocytes are analogous to various renal tubular cells, in terms of ion transporter expression and function. During embryonic development, ionocyte progenitors develop from epidermal stem cells and then differentiate into different types of ionocyte through a positive regulatory loop of Foxi3a/-3b and other transcription factors. Several hormones, including cortisol, vitamin D, stanniocalcin-1, calcitonin, and isotocin, were found to participate in the control pathways of ionic homeostasis by precisely studying the target ion transport pathways, ion transporters, or ionocytes of the hormonal actions. In conclusion, the zebrafish model not only enhances our understanding of body fluid ion homeostasis and hormonal control in fish but also informs studies on
\end{abstract}

\section{P.-P. Hwang $(\bowtie)$}

Institute of Cellular and Organismic Biology, Academia Sinica,

Taipei 11529, Taiwan

e-mail: pphwang@gate.sinica.edu.tw

M.-Y. Chou

Laboratory for Developmental Gene Regulation, RIKEN Brain

Science Institute, 2-1 Hirosawa, Wako, Saitama 351-0198, Japan mammals and other animal species, thereby providing new insights into related fields.

Keywords Ion uptake - Acid-base regulation . Transepithelial transport · Differentiation · Hormone · Zebrafish

\section{Introduction}

All terrestrial and some aquatic vertebrates have successfully evolved mechanisms to regulate ionic and osmotic homeostasis of their body fluids, which enables cellular activities and physiological processes to operate normally in these animals. In terrestrial vertebrates, these regulatory mechanisms are mainly performed by the kidneys. In aquatic vertebrates such as fish, the gills are the major extra-renal organ involved in body fluid ionic/osmotic homeostasis [28, 51, 52].

As a model organism, zebrafish (Danio rerio) has a number of advantages, including the availability of genetic databases, applicability of forward/reverse genetic manipulation and cell biological approaches, transparent embryos with rapid development, and short life cycle. As such, zebrafish is an emerging and competent model for developmental biology, neurobiology, and human diseases. Furthermore, several research groups have applied the zebrafish model to the study of integrative and regulatory physiology and, in particular, the epithelial transport that is associated with body fluid ionic/osmotic homeostasis. Zebrafish, a freshwater teleost fish, inhabits a hypotonic freshwater environment with low ionic concentrations (compared to those in the plasma) and fluctuant $\mathrm{pH}$ and therefore has to actively absorb ions from and secrete acid (or base) and ammonia to the environment, in order to maintain body fluid homeostasis. The majority of these tasks related to ion regulation are performed by the gills, and ionocytes within the gills are the major cell types involved in epithelial ion transport [28]. 
Recently, four types of zebrafish ionocyte were identified to be responsible for the transport of various ions by distinct sets of ion transporters (Fig. 1), and these ionocytes are analogous to the transporting cells in different segments of the mammalian kidney, in terms of the expression and function of ion transporters. During the embryonic stages before the gills are fully functional, ionocytes initially develop in the embryonic skin, becoming functional at around $24 \mathrm{~h}$ post-fertilization (hpf) (zebrafish embryos usually hatch between 48 and $72 \mathrm{hpf}$ at $28.5^{\circ} \mathrm{C}$ ). Consequently, zebrafish embryos serve as a powerful in vivo model in which to study epithelial ion transport physiology and regulation, for the following reasons: First, ionocytes in embryonic skin are directly exposed to the environment, and their morphology and ion transporter expression can be readily observed in situ without further anatomic manipulation; second, ion fluxes (representing ion transporter function) can be directly examined by noninvasive electrophysiological approaches or the use of tracers (fluorescent probes or radioisotopes); third, the effects of transporter (or ionocyte) loss- or gain-of-function can be analyzed within 1-5 days post-fertilization, at which time the injected morpholinos or mRNAs are effective; and finally, incubation of zebrafish embryos (or adults) in media with different ionic compositions (including changes in $\mathrm{Na}^{+}, \mathrm{Cl}^{-}$, $\mathrm{Ca}^{2+}, \mathrm{NH}_{4}^{+}, \mathrm{pH}$, or others) can facilitate investigation of transport function and regulation of a specific ion by the target transporter (or ionocyte).

The topic of ion regulation in zebrafish has been summarized in some comprehensive fish reviews [23, 26, 27, 35, $50,51,68]$ and specific reviews on zebrafish $[15,49,52]$.
The present review is intended to highlight the recent progress in the identification and functional analysis of ion transporters in different types of ionocyte, the ionocyte differentiation pathways, and functional regulation by hormones in zebrafish embryonic skin and gills.

\section{Identification and functional analysis of ionocytes}

\section{$\mathrm{H}^{+}$-ATPase-rich ionocytes}

$\mathrm{H}^{+}$-ATPase-rich (HR) ionocytes contain apical $\mathrm{H}^{+}$-ATPase (HA) and were first identified as the major cell type responsible for the acid secretion function of the embryonic skin and gills, as determined by a non-invasive scanning ionselective electrode technique (SIET) and loss-of-function approach $[42,75]$. Similar approaches were used to identify co-localization of $\mathrm{Na}^{+} / \mathrm{H}^{+}$exchanger (NHE3b) and Rhesus glycoprotein (Rhcg1) at the apical membrane and $\mathrm{Cl}^{-} / \mathrm{HCO}_{3}{ }^{-}$exchanger (AE1b) and $\mathrm{Na}^{+}-\mathrm{K}^{+}$-ATPase (NKA) $\alpha 1$ subunit (atp1a1a.5) at the basolateral membrane; they were also used to identify two carbonic anhydrases (membrane-bound CA15a and cytosolic CA2-like a) in HR ionocytes and to demonstrate that the epithelial transport functions of $\mathrm{HR}$ cells are related to not only $\mathrm{H}^{+}$secretion but also to $\mathrm{Na}^{+}$and $\mathrm{HCO}_{3}{ }^{-}$uptake and ammonium excretion $[24,72,73,76,83,92,119]$. HR-type ionocytes in zebrafish are analogous to proximal tubular cells and type A intercalated cells of the kidney, in terms of transporter expression and function $[13,98,113]$. The activity of $\mathrm{H}^{+}, \mathrm{NH}_{4}^{+}$, and

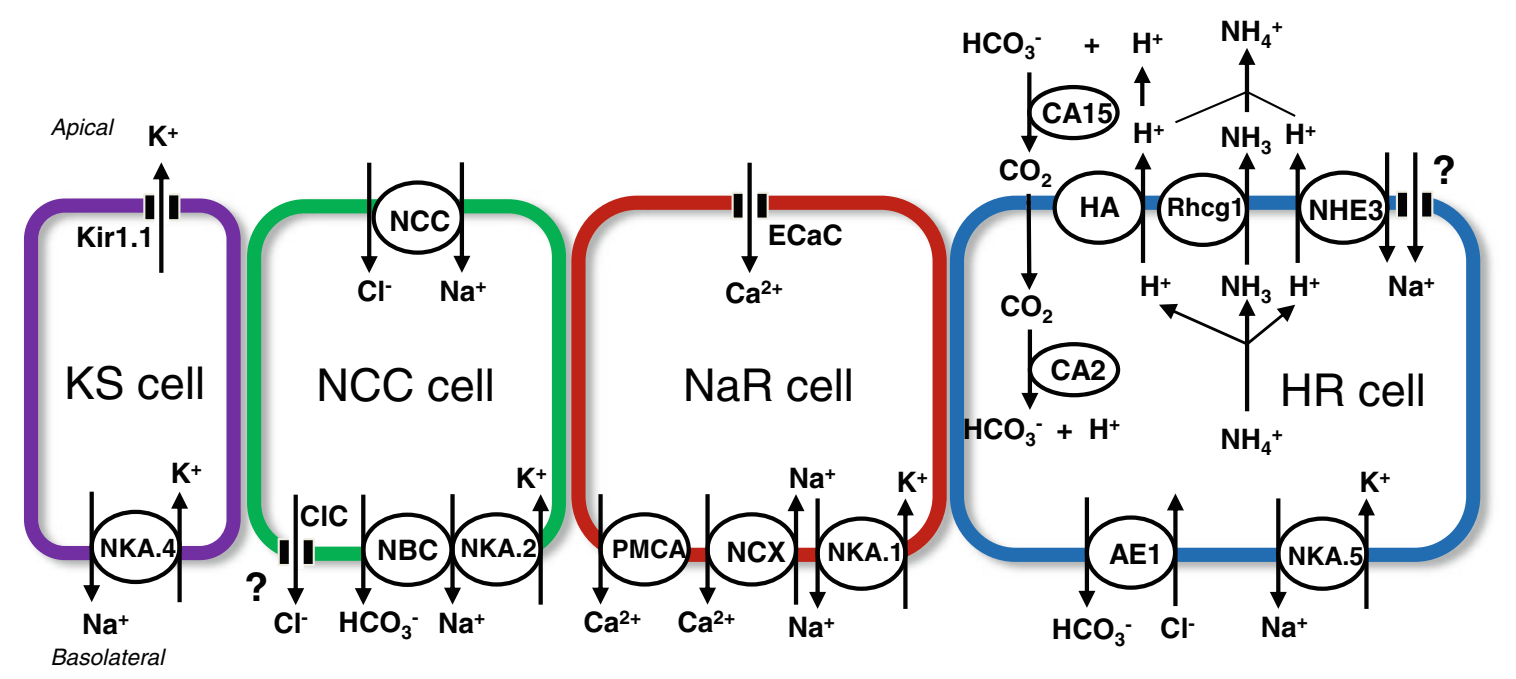

Fig. 1 Ionocytes in zebrafish. Four types of ionocyte have been identified: $\mathrm{H}^{+}$-ATPase-rich $(H R), \mathrm{Na}^{+}-\mathrm{K}^{+}$-ATPase-rich $(\mathrm{NaR}), \mathrm{Na}^{+}-$ $\mathrm{Cl}^{-}$cotransporter $(N C C)$, and $\mathrm{K}^{+}$-secreting $(K S)$ cells. Details of the transport pathways are given in the text ("Identification and functional analysis of ionocytes" section). $A E 1$ anion exchanger 1b, CA2 carbonic anhydrase 2-like a, CA15) carbonic anhydrase $15 \mathrm{a}$, $C l C \mathrm{Cl}^{-}$channel, $E C a C$ epithelial $\mathrm{Ca}^{2+}$ channel, $H A \mathrm{H}^{+}$-ATPase, ROMK an ortholog of the mammalian renal outer medullary $\mathrm{K}^{+}$channel (Kir1.1), $N B C l$ electrogenic $\mathrm{Na}^{+}-\mathrm{HO}_{3}{ }^{-}$cotransporter $1 \mathrm{~b}, \mathrm{NCX} \mathrm{Na}^{+} / \mathrm{Ca}^{2+}$ exchanger $1 \mathrm{~b}, N H E \mathrm{Na}^{+} / \mathrm{H}^{+}$exchanger $3 \mathrm{~b}, N A K .1 \sim 5 \mathrm{Na}^{+}-\mathrm{K}^{+}$-ATPase $\alpha 1$ subunit subtypes (atp1a1a.1 5), PMCA plasma membrane $\mathrm{Ca}^{2+}$-ATPase 2, Rhcgl rhesus glycoprotein. Question mark indicates unidentified transport pathways 
$\mathrm{Na}^{+}$, and $\mathrm{Na}^{+}$accumulation can be examined in real time at a single ionocyte or in the body skin of a live embryo by SIET $[75,92,93]$ and sodium green fluorescence microscopy [24], respectively. Given these advantages, HR cells in the zebrafish embryonic skin may provide an alternative in vivo model for research into the related epithelial transport physiology in vertebrates.

Both HA and NHE3b enable $\mathrm{H}^{+}$secretion across the apical membrane of HR cells in zebrafish. Recent studies have shown that HA knockdown or bafilomycin A1 (an HA inhibitor) treatment suppressed $67-75 \%$ of the apical $\mathrm{H}^{+}$ activity in HR cells [91], while NHE3b knockdown or EIPA (an NHE3 inhibitor) treatment only impaired $27-29 \%$ of the activity [93]. Therefore, it seems that HA plays a greater role than HNE3b in the acid secretion function of zebrafish HR cells. HA-linked epithelial $\mathrm{Na}^{+}$channel $(\mathrm{ENaC})$ and NHE have been long considered the two major $\mathrm{Na}^{+}$uptake pathways in fish [28, 51]. Esaki et al. [24] provided pharmacological evidence to support the role of $\mathrm{HA}, \mathrm{ENaC}$, and NHE3b in apical $\mathrm{Na}^{+}$uptake in zebrafish: bafilomycin A1, amiloride $\left(10^{-5}\right.$ and $\left.10^{-4} \mathrm{M}\right)$, and EIPA suppressed $\mathrm{Na}^{+}$ influx (as detected by ${ }^{24} \mathrm{Na}^{+}$tracing) or $\mathrm{Na}^{+}$accumulation (as detected by sodium green $\left(10^{-5} \mathrm{M}\right.$ amiloride had no effect)) in embryonic skin HR cells. Notably, orthologs of mammalian $\mathrm{ENaC}$ have not been detected in the genomes of zebrafish and other teleosts, and thus, the identity of the $\mathrm{ENaC}$ in fish remains to be determined. Supporting Esaki's data, loss of function of HA was found to decrease $\mathrm{Na}^{+}$ content in zebrafish embryos reared in a low- $\mathrm{Na}^{+}$medium [42]. On the other hand, a recent study by Kumai and Perry [67] did not find a significant effect of EIPA on $\mathrm{Na}^{+}$influx in zebrafish embryos reared in normal freshwater (the similar ion compositions in freshwater and inhibitor concentration as in Esaki's study), bringing the role of NHE3b in zebrafish $\mathrm{Na}^{+}$uptake into question. Further investigation is required to reconcile the inconsistencies between the two studies. To this end, we found that NHE3b knockdown reduced zebrafish $\mathrm{Na}^{+}$content under either normal freshwater (unpublished data by Chang WJ and Hwang PP; Fig. 2) or low- $\mathrm{Na}^{+}$freshwater [93] conditions, and this more convincing molecular physiological approach supports a role for NHE3b in the $\mathrm{Na}^{+}$absorption function of HR cells.

Unlike mammals, which excrete urea as the major carrier of waste nitrogen, teleosts are predominantly ammonotelic, i.e., they mainly excrete ammonia. As teleosts can directly excrete ammonia into the surrounding water, they do not need to waste energy in converting it into less-toxic urea. Most ammonia excretion is accomplished by the gills or skin (the latter during embryonic stages). Our understanding of the mechanism and regulation of ammonia excretion and its associated roles in fish gill/skin $\mathrm{Na}^{+}$uptake and acid secretion by specific types of ionocyte has been increased by the recent discovery of $\mathrm{Rh}$ proteins and the application of

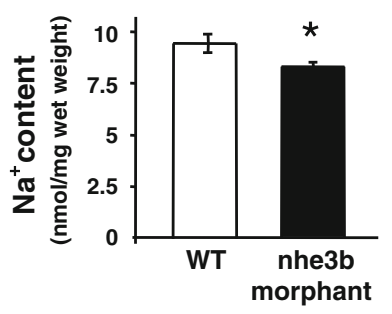

Fig. 2 Effect of nhe $3 b$ knockdown on $\mathrm{Na}^{+}$content in zebrafish embryos at 3 day post-fertilization. Specific morpholinos (following [92]) were microinjected into 1 4 cell-stage embryos incubated in normal freshwater (about $500 \mu \mathrm{M} \mathrm{NaCl}$ and $20 \mu \mathrm{M} \mathrm{Ca}^{2+}$ ). Whole-body $\mathrm{Na}^{+}$ content was measured by atomic absorption spectrophotometry. Data are expressed as the mean $\pm \mathrm{SD}(n=6)$. A significant difference (Student's $t$ test, $p<0.001)$ was found between wild-type $(W T)$ and nhe $3 b$ morphant embryos

the SIET technique to fish embryos. Fish gills were thought to predominately excrete $\mathrm{NH}_{3}$ gas rather than ionic $\mathrm{NH}_{4}^{+}$, based on early studies on "acid-trapping" ammonia excretion, through which acidification of the boundary layer adjacent to the gill surface facilitates the excretion of ammonia [116]. In studies on rainbow trout, $\mathrm{CO}_{2}$ excretion by the gills was suggested to be the major source of the acidic layer, and Rhcg, HA, NHE, and $\mathrm{ENaC}$ were proposed to work together as a functional metabolon [117]. However, prior to recent studies on zebrafish, there was no evidence to support co-localization of these transporters, or in vivo molecular physiological data to support the proposed model. Rhcg1 has since been shown to co-localize with HA and NHE3b in the apical membrane of zebrafish HR cells [83, 92], and knockdown of Rhcg1 was found to suppress apical $\mathrm{NH}_{4}{ }^{+}$excretion in the cells [92]. Moreover, both HA (or NHE3b) knockdown or treatment with bafilomycin A1 (or EIPA) resulted in a decrease in apical $\mathrm{H}^{+}$activity accompanied by impaired $\mathrm{NH}_{4}{ }^{+}$excretion, providing in vivo evidences to demonstrate that HA or NHE3b may provide an alternative $\mathrm{H}^{+}$source for "acid-trapping" ammonia excretion in zebrafish [92, 93]. Besides Rhcg1, Rhag and Rhbg were also found to be involved in zebrafish $\mathrm{NH}_{4}{ }^{+}$excretion, as determined from loss-of-function experiments; however, the pattern of mRNA and protein expression for these two transporters does not appear to be related to specific ionocytes [11].

The coupling of NHE3 and Rhcg 1 not only mediates acidtrapping ammonia excretion but also mediates $\mathrm{Na}^{+}$uptake by ionocytes. By using SIET to probe the real-time $\mathrm{Na}^{+}, \mathrm{NH}_{4}^{+}$, and $\mathrm{H}^{+}$gradients of ionocytes in the embryonic skin of medaka, another teleost species, Wu and colleagues [118] found that $\mathrm{Na}^{+}$uptake and ammonia excretion by ionocytes are tightly associated. Acute exposure to high $\mathrm{NH}_{4}{ }^{+}$was found to simultaneously suppress $\mathrm{NH}_{4}^{+}$excretion and $\mathrm{Na}^{+}$uptake in zebrafish embryos acclimated to low- $\mathrm{Na}^{+}$and low-pH water $[67,93]$. Moreover, acclimation to low $-\mathrm{Na}^{+}$media stimulated transcription of the genes encoding Rhcg 1 and NHE3b in the 
gill, as well as $\mathrm{NH}_{4}^{+}$excretion/ $\mathrm{Na}^{+}$uptake in zebrafish [93]. Moreover, X-ray crystallographic studies on the molecular structures of bacterial homologues of Rh proteins, AmtB and $\mathrm{NeRh}$, suggested these proteins form ammonia channels that recruit intracellular $\mathrm{NH}_{4}^{+}$, release $\mathrm{H}^{+}$, and transport $\mathrm{NH}_{3}$ through the transmembrane hydrophobic pore, ultimately releasing $\mathrm{NH}_{4}^{+}$by recruiting $\mathrm{H}^{+}$to the extracellular side [55, 61]. This deprotonating and protonating action on the inside and outside of the membrane, respectively, may create a favorable $\mathrm{H}^{+}$gradient to drive the operation of electroneutral NHE3b in zebrafish HR cells. This model was recently supported by genetic knockdown experiments, in which loss of function of Rhcg1 decreased both $\mathrm{NH}_{4}{ }^{+}$excretion and $\mathrm{Na}^{+}$ uptake in zebrafish embryos acclimated to low- $\mathrm{Na}^{+}$water [93] or acidic water [67]. Unlike mammalian renal cells, gill/skin ionocytes in aquatic animals encounter freshwater with less than $1 \mathrm{mM} \mathrm{Na}^{+}$, a theoretically thermodynamic constraint on the operation of NHE [4]. The proposed ammoniumdependent sodium uptake model $[52,67,93,118]$ may help resolve the long-debated questions regarding the driving mechanisms of NHE in the ionocytes of freshwater fish or other aquatic animals.

Epithelial $\mathrm{Na}^{+}$uptake and $\mathrm{H}^{+}$secretion (equivalent to $\mathrm{HCO}_{3}{ }^{-}$uptake) in zebrafish $\mathrm{HR}$ cells requires carbonate anhydrases and other basolateral transporters, a requirement shared by mammalian kidney proximal tubules and collecting ducts [87]. In zebrafish HR cells, apical NHE3b and $\mathrm{H}^{+}$ATPase transport $\mathrm{H}^{+}$out of cells, and $\mathrm{H}^{+}$combines with environmental $\mathrm{HCO}_{3}{ }^{-}$to generate $\mathrm{H}_{2} \mathrm{O}$ and $\mathrm{CO}_{2}$, as catalyzed by $\mathrm{CA} 15 \mathrm{a}$ (an ortholog of mammalian $\mathrm{CA} 4$ ). $\mathrm{CO}_{2}$ enters cells and is hydrated by $\mathrm{Ca} 2$ like-a (an ortholog of mammalian CA2) to form $\mathrm{H}^{+}$and $\mathrm{HCO}_{3}{ }^{-}$. Basolateral AE1b (an ortholog of mammalian AE1) extrudes cytosolic $\mathrm{HCO}_{3}{ }^{-}$down the $\mathrm{Cl}^{-}$ gradient to fulfill the epithelial acid-secreting function, while basolateral NKA is responsible for the excretion of $\mathrm{Na}^{+}$. On the other hand, $\mathrm{K}^{+}-\mathrm{Cl}^{-}$cotransporter $(\mathrm{KCC})$ recycles the $\mathrm{Cl}^{-}$ accumulated by the action of basolateral AE1 in mammalian type A intercalated cells [107]. Further studies are needed to determine if an ortholog(s) of $\mathrm{KCC}$ is also expressed and involved in $\mathrm{Cl}^{-}$recycling in zebrafish HR cells.

\section{$\mathrm{Na}^{+}-\mathrm{K}^{+}$-ATPase-rich ionocytes}

$\mathrm{Na}^{+}-\mathrm{K}^{+}$-ATPase-rich $(\mathrm{NaR})$ cells were initially identified as a specific group of ionocytes distinct from HR cells through labeling of zebrafish embryonic skin with an anti-chicken NKA $\alpha$ subunit monoclonal antibody ( $\alpha 5$, Developmental Studies Hybridoma Bank, University of Iowa) [74] (Fig. 1). A minority (about 20-30\%) of NaR cells express epithelial $\mathrm{Ca}^{+}$channel $(\mathrm{ECaC})$ mRNA during early embryonic stages (around $36 \mathrm{hpf}$ ), and the number of NaR cells expressing $\mathrm{ECaC}$ increases following embryonic development, reaching up to $90 \%$ in adult gills $[74,85]$. Six isoforms of plasma membrane $\mathrm{Ca}^{2+}$-ATPase (PMCA) and seven isoforms of $\mathrm{Na}^{+} / \mathrm{Ca}^{2+}$ exchanger (NCX) have been identified in zebrafish, of which only PMCA2 and NCX1b were found to co-localize in NaR cells, as determined by triple in situ hybridization and immunocytochemistry [74]; zebrafish $\mathrm{NaR}$ cells exhibit a similar set of $\mathrm{Ca}^{2+}$ transporters to mammalian renal and intestinal $\mathrm{Ca}^{2+}$-absorption cells [40]. Moreover, of six NKA $\alpha 1$ subunit genes, only atpla1a.1 was expressed in NaR cells [73]. The physiological role of ECaC in $\mathrm{Ca}^{2+}$ uptake in zebrafish was demonstrated by knockdown with specific morpholinos [104] and by low-Ca ${ }^{2+}$ acclimation, which was found to stimulate $\mathrm{ECaC}$ mRNA expression and $\mathrm{Ca}^{2+}$ influx and increase the number of $\mathrm{ECaC}$-expressing ionocytes [74, 85]. In mammals, transepithelial $\mathrm{Ca}^{2+}$ transport through apical influx, cytosolic diffusion, and basolateral efflux are tightly connected by TRPV5/6 (orthologs of zebrafish ECaC), NCX1, and PMCA1b; however, TRPV5 (or TRPV6) transporters appear to constitute the rate-limiting step for $\mathrm{Ca}^{2+}$ uptake [40]. A similar model was proposed early on for fish gills [30], but molecular evidence for the identity of the relevant transporters was lacking until recent studies on zebrafish ([74, 85]; see above). An early enzyme kinetic study found that the basolateral $\mathrm{Ca}^{2+}$ extrusion mediated by PMCA and NCX in fish gills is far below its maximum capacity [29]. Acclimation of zebrafish to a low- $\mathrm{Ca}^{2+}$ environment, which is known to stimulate $\mathrm{Ca}^{2+}$ uptake [85], was also found to increase mRNA expression of $\mathrm{ECaC}$, but not zPMCA2 or zNCX1b [74]. This implies that steady-state expression of PMCA2 and NCX1b may support transepithelial transport under most environmental conditions. Moreover, expression of $\mathrm{ECaC}$, but not that of PMCA2 and NCX1b, is affected by hormones, including stanniocalcin [104], cortisol [78], and vitamin D [77]. Taken together, these findings suggest that the role of $\mathrm{ECaC}$ as the major regulatory target for transepithelial $\mathrm{Ca}^{2+}$ uptake is conserved from fish to mammals.

The expression patterns of $\mathrm{Ca}^{2+}$ transporter isoforms differ between mammals and zebrafish, and this may be advantageous for elucidating mammalian $\mathrm{Ca}^{2+}$ handling in a zebrafish model. In zebrafish, the NCX1b isoform is required for $\mathrm{Ca}^{2+}$ extrusion in gill/skin ionocytes, and the NCX1a isoform is expressed specifically in heart; mutations in the latter cause cardiac fibrillations [71]. Conversely, a single NXC1 performs the roles of both NCX1a and NCX1b in mammals, thus making it difficult to investigate the specific role of NCX1 in renal $\mathrm{Ca}^{2+}$ transport by gene knockout without inducing cardiac defects and mortality $[40,65]$. As such, zebrafish may provide an alternative model in which to study the role and functional regulation of NCX1a in body fluid $\mathrm{Ca}^{2+}$ homeostasis without inducing heart failure. Another difference in isoform number between species is observed for $\mathrm{ECaC}$ : A single isoform is required 
for transepithelial $\mathrm{Ca}^{2+}$ transport in zebrafish, while two mammalian isoforms, TRPV5 and TRPV6, function as the apical $\mathrm{Ca}^{2+}$ entry pathway of the transepithelial $\mathrm{Ca}^{2+}$ transport mechanisms in mammalian kidneys and intestines. Studies on this pathway and its functional regulation by single knockdown of TRPV5 (or TRPV6) are complicated by functional redundancy and compensation between the two paralogous genes [40, 105]. A zebrafish mutant with a loss of function of $\mathrm{ECaC}$ (matt-und-schlapp) was found to exhibit impaired $\mathrm{Ca}^{2+}$ uptake and severe defects in bone formation, suggesting this mutant may serve as an alternative in vivo model for the study of this essential physiological process [105].

\section{$\mathrm{Na}^{+}-\mathrm{Cl}^{-}$cotransporter-expressing ionocytes}

Another subtype of zebrafish skin/gill ionocytes, $\mathrm{Na}^{+}-\mathrm{Cl}^{-}$ cotransporter (NCC) cells, was recently found to be analogous to the mammalian distal convoluted tubular cells that express $\mathrm{Na}^{+}-\mathrm{Cl}^{-}$-cotransporters and participate in the absorption of $\mathrm{Na}^{+}$and $\mathrm{Cl}^{-}$[111] (Fig. 1). In zebrafish, slc12a10.2 (an NCC-like member distinct from slc12a3 (an ortholog of mammalian SLC12A3)) is localized to a specific group of ionocytes that are different from the previously identified HR and NaR cells. Furthermore, metolazone (a specific NCC inhibitor) has dose-dependent inhibitory effects on influx of both $\mathrm{Na}^{+}$and $\mathrm{Cl}^{-}$in intact embryos [111]. NCC lossof-function decreased the $\mathrm{Cl}^{-}$content in the morphants, demonstrating the physiological role of NCCs in transepithelial $\mathrm{Cl}^{-}$ uptake in zebrafish [111]. As $\mathrm{Na}^{+}$uptake in zebrafish occurs mainly through the actions of NHE3b $\left([25,119]\right.$; see " $\mathrm{H}^{+}-$ ATPase-rich ionocytes" section), NCC may play a minor or supplemental role. Metolazone was reported to have no effect on sodium green (a fluorescent $\mathrm{Na}^{+}$probe) accumulation in zebrafish HR cells [24], and NCC knockdown resulted in an increase in $\mathrm{Na}^{+}$content and a concomitant stimulation of NHE3b expression in 5-day pf morphants [111]. In addition, knockdown of glial cell missing 2 (encoding Gcm2, a transcription factor that specifically affects differentiation of NHE3b-expressing HR cells; see "Proliferation and differentiation of ionocytes" section) resulted in a loss of HR cells (thus impairing $\mathrm{Na}^{+}$uptake) with a concomitant increase in the number of NCC cells in zebrafish morphants [51, 97]. Interestingly, this functional redundancy between NHE3 and $\mathrm{NCC}$ in $\mathrm{Na}^{+}$homeostasis appears to be conserved in zebrafish and mammals. In mammalian kidneys, proximal tubules perform bulk reabsorption of $\mathrm{Na}^{+}$via NHE3, and further, finetuning of $\mathrm{Na}$ reabsorption is achieved by other redundant pathways, including the distal convoluted tubular NCC [36].

The lumen of mammalian distal convoluted tubules contains a $\mathrm{Na}^{+}$concentration of $35-77 \mathrm{mM}$ to drive the operation of electroneutral NCC [37]. Unlike the mammalian NCC, the zebrafish NCC may not, theoretically, be driven by the $0.4-0.7-\mathrm{mM} \mathrm{Na}^{+} / \mathrm{Cl}^{-}$concentration of ambient freshwater (local tap water) to which they are exposed. According to recent SIET measurements at the apical membrane of tilapia embryonic ionocytes [41], the activity of $\mathrm{Na}^{+} / \mathrm{Cl}^{-}$in the microenvironment appeared to be higher than that in ambient freshwater, probably due to outward $\mathrm{Na}^{+} / \mathrm{Cl}^{-}$ fluxes from neighboring pavement cells, and these ionic gradients may be high enough to drive the NCC. However, this hypothesis remains to be tested in zebrafish NCC cells. It may be addressed by examining whether or not the zebrafish NCC is different from its mammalian equivalent in terms of transport kinetics or stoichiometry.

Basolateral transporters in zebrafish NCC ionocytes include NKA $\alpha 1$ subunit (atp1a1a.2) and $\mathrm{Na}^{+}-\mathrm{HCO}_{3}{ }^{-}$ cotransporter (NBCe1b) $[72,73]$. The subunit atpla1a.2 was found to be specifically localized in NCC ionocytes, and its mRNA expression is stimulated by low- $\mathrm{Cl}^{-}$freshwater, suggesting its involvement in the $\mathrm{Cl}^{-}$uptake mechanism of NCC cells [73, 111]. Of the 12 isoforms of the zebrafish slc $4 a$ family, only two, slc4a1b (AE1b) and slc4a4b (NBCelb), exhibited a salt-and-pepper-like ionocyte pattern in mRNA expression in zebrafish skin and gill $[72,95,96,100]$. AE1b is co-expressed with NHE3b/HA in HR ionocytes as described above, while NBCe1b and NCC are co-expressed in NCC cells [72]. Apical NCC transports $\mathrm{Na}^{+}$into the cells, and basolateral NBCe1b and NKA (atp1a1a.2) may extrude intracellular $\mathrm{Na}^{+}$out of the cells; however, molecular physiological evidence in support of these functions is not yet available. In mammalian distal convoluted tubular cells, the $\mathrm{Cl}^{-}$channels, $\mathrm{ClC}-\mathrm{K} 1$ and $\mathrm{ClC}-\mathrm{K} 2$, act as basolateral transporters to extrude $\mathrm{Cl}^{-}$[88]. An ortholog of mammalian $\mathrm{ClC}$ co-localizes with NCC in gill ionocytes of tilapia, a teleost species [102]. Future identification of $\mathrm{ClC}$ member(s) in zebrafish is necessary for a comprehensive understanding of the transepithelial transport mechanisms in zebrafish NCC ionocytes.

\section{$\mathrm{K}^{+}$-secreting ionocytes}

The mRNA of a subtype of the NKA $\alpha 1$ subunit (atp1a1a.4) was found to be expressed in a specific group of ionocytes in zebrafish, distinct from the HR, $\mathrm{NaR}$, and $\mathrm{NCC}$ ionocytes [73] (Fig. 1). Identification and functional analysis of these atp1a1a.4-expressing cells remained unresolved [51, 52, 73] until a recent study investigating a $\mathrm{K}^{+}$channel, Kir1.1, an ortholog of the mammalian renal outer medullary $\mathrm{K}^{+}$channel (ROMK) [1]. Kir1.1 mRNA was reported to be colocalized with atp1a1a.4 in the same type of ionocytes in zebrafish embryonic skin, and loss of function of Kir1.1 resulted in transient tachycardia followed by bradycardia [1], effects similar to that observed in hyperkalemia in human [59]. These Kir1.1-expressing ionocytes were proposed to be $\mathrm{K}^{+}$-secreting (KS) cells [1], although there is no physiological evidence to demonstrate $\mathrm{K}^{+}$currents in $\mathrm{KS}$ cells. In mammalian kidneys, the ROMK protein is 
localized to the apical membrane of cells of the thick ascending limb and distal nephron and is required for the $\mathrm{K}^{+}$secretion pathway and thus $\mathrm{K}^{+}$homeostasis, as well as being involved in driving the relevant transporters to absorb $\mathrm{Na}^{+}$and/or $\mathrm{Cl}^{-}$and paracellular $\mathrm{Na}^{+} / \mathrm{Ca}^{2+} / \mathrm{Mg}^{2+}$ transport $[39,114]$. From an evolutionary point of view, the physiological functions of the mammalian ROMK may also be conserved, to a certain extent, in zebrafish. Identification of other co-expressed transporters and functional analysis of those transporters in the presumed KS cells are necessary to explore the physiological roles of KS cells in zebrafish.

\section{Other transporting ionocytes}

In the mammalian collecting duct, type B intercalated cells coexpress apical pendrin (SLC26A4) and basolateral HA and play a major role in $\mathrm{HCO}_{3}{ }^{-}$secretion (equivalent to $\mathrm{H}^{+}$absorption) for body fluid acid-base homeostasis [107, 109]. Similarly, three orthologs of mammalian pendrin, slc26a3, slc4, and slc6c, were recently identified in zebrafish $[8,86]$. The encoding mRNA of these proteins (and slc26a3 protein itself) is expressed in certain type(s) of cells in the embryonic and adult gills, and a minority $(<10 \%)$ of slc26a3-expressing cells also co-expresses basolateral NKA $[8,86]$. Acclimation to low-Cl ${ }^{-}$or high- $\mathrm{NaHCO}_{3}$ freshwater was found to stimulate the transcription of these three genes in the gill and to enhance $\mathrm{Cl}^{-}$uptake in adult zebrafish, suggesting a role for these genes in apical $\mathrm{Cl}^{-} / \mathrm{HCO}_{3}{ }^{-}$exchange in zebrafish cells [86]. This hypothesis was further supported by loss-offunction experiments in which knockdown of all three genes impaired $\mathrm{Cl}^{-}$uptake in morphants raised in low-Cl- freshwater [8]. Basolateral HA and/or other enzymes (e.g., carbonic anhydrases) are essential for transepithelial $\mathrm{Cl}^{-}$uptake $/ \mathrm{HCO}_{3}{ }^{-}$ secretion. Whether these proteins co-localize with slc26 proteins, and if so, the functional implications of this colocalization, remain to be addressed. Moreover, the identity of the driving mechanism for apical $\mathrm{Cl}^{-} / \mathrm{HCO}_{3}{ }^{-}$exchange in zebrafish gill/skin ionocytes encountering a freshwater environment remains unclear, but investigation of the stoichiometry of the zebrafish slc 26 members may provide answers. It is unknown if these slc26 members are expressed in the same type of cells or in one (or more) type of the identified ionocytes (HR, NaR, NCC, or KS cells), and therefore, the slc26-expressing cells are not presented in the proposed model (Fig. 1).

\section{Proliferation and differentiation of ionocytes}

Proliferation and differentiation of ionocytes are means by which ionocyte function is regulated in zebrafish during acclimation to harsh environments. These processes have become more amenable to study following the recent use of genetic and molecular approaches to explore the molecular mechanisms of ionocyte development [52]. Ionocytes are derived from non-neural ectoderm that express $\Delta \mathrm{Np} 63$, a marker (and requirement) of proliferating epithelial cells [54]. After gastrulation (bud stage), two specification markers of ionocytes, forkhead box I3a (Foxi3a) and DeltaC (a ligand of Notch signaling), are expressed in certain $\Delta \mathrm{Np63-positive} \mathrm{epidermal} \mathrm{cells} \mathrm{that} \mathrm{further} \mathrm{differentiate}$ into ionocyte progenitors [45]. The epidermal ionocyte progenitors undergo lateral inhibition through Notch signaling to inhibit the expression of Foxi3a in neighboring cells; Notch signaling maintains the cell fate of the keratinocyte lineage [45]. As development proceeds, $\Delta \mathrm{Np} 63$ expression in epidermal ionocyte progenitors is downregulated at the 14-somite stage, and Foxi3a activates cell differentiation of ionocytes [45].

At least four subtypes of ionocytes have been identified: HR, NaR, NCC, and KS cells (see "Identification and functional analysis of ionocytes" section). However, the mechanisms underlying ionocyte subtype specification remain unclear. Hsiao et al. [45] demonstrated that Foxi3a turns on the expression of Foxi3b at the 5-somite stage and that the positive regulatory loop between Foxi3a and Foxi3b functions as a master regulator for specifying epidermal ionocyte progenitors [45]. Later on, Foxi3a is downregulated in NaR cells, while Foxi3b is downregulated in HR cells [45, 54]. Foxi3a and Foxi3b expression in HR cells and NaR cells seems to be critical for the specification of ionocyte subtypes [24, 45, 54]. Foxi3a also induces expression of Jagged 2a and Jagged 2b, which are Notch ligands expressed in differentiating ionocytes; this suggests that Notch signaling may also be involved in the specification of ionocyte subtypes [54].

In addition to Foxi3 and Notch signaling, a cell faterelated transcription factor, $\mathrm{Gcm} 2$, has been reported to control the specification of HR cells [14]. Knockdown of $\mathrm{Gcm} 2$ completely abolished HR cell formation, but had no effects on NaR cell density at $72 \mathrm{hpf}$, indicating that $\mathrm{Gcm} 2$ is essential for differentiation of HR, but not NaR cells [14]. Gcm2 may control HR cell differentiation via interactions with Foxi3a. Esaki et al. [25] demonstrated that knockdown of Gcm 2 suppressed Foxi3a expression at 24 hpf [25]. This suggests that Gcm 2 may modulate expression of Foxi3a and Foxi3b and, as a result, determine the $\mathrm{NaR}$ and HR cell lineages. Esaki et al. [25] also identified another transcription factor, Foxil, which is required for HR cell differentiation [25]. Knockdown of Foxil decreased expression of DeltaC and Foxi3a and impaired formation of HR cells [25]. However, NaR cell differentiation was unaffected in Foxil morphants, making the role of Foxil in ionocyte differentiation unclear. Alternatively, Foxil may control HR cell differentiation through an indirect pathway. 
Ionocyte differentiation in adult zebrafish remains poorly understood; however, recent studies have indicated that differentiation of adult ionocytes is also mediated through Foxi3a $[18,21]$. During cold acclimation, zebrafish ionocyte differentiation is stimulated through an increase in Foxi3a expression, and both cell proliferation and apoptosis in the gill epithelial cells are decreased to extend the cell lifespan for enhancing ionocyte function [18]. An in vitro experiment using cultured adult zebrafish gills revealed that cortisol treatment upregulated expression of Foxi3a and Foxi3b and increased ionocyte numbers in the gills [21]. Moreover, after acclimatizing to an acidic environment, $\mathrm{Gcm} 2$ expression and HR cell numbers were increased in the gills of adult zebrafish, suggesting that the $\mathrm{H}^{+}$secreting function of $\mathrm{HR}$ cells in the gills is enhanced by a Gcm2-mediated acceleration of HR cell differentiation [14]. It seems likely that differentiation of adult gill ionocytes shares the same or similar regulatory pathways with that of embryonic ionocytes.

Zebrafish ionocytes are analogous to mammalian kidney cells in terms of the expression and function of the relevant transporters, as described above. Interestingly, zebrafish ionocytes exhibit a conserved cell differentiation pathway, as also observed for mammalian intercalated cells [2]. Previous studies have indicated that type $B$ intercalated cells are the progenitors of the type A cells, and this conversion arises from hensin (an extracellular matrix protein)-mediated differentiation plasticity in response to changes in extracellular $\mathrm{pH}[33,90]$. Intercalated cells are derived from the ureteric bud, an epithelial structure that buds off the Wolffian duct $[58,99]$; Notch signaling determines the cell lineages of principle and intercalated cells [56]. In addition, Foxil was reported to be critical for the differentiation of intercalated cells, based on the finding that intercalated cells were absent from the collecting duct in Foxi1-null mice [9, 106]. A retrospective view of the related research indicates that the discovery of the role of Foxil in intercalated cell differentiation [9] gave rise to pioneer studies on zebrafish Foxi3a/3b $[24,45,54]$ and subsequently the first model for the molecular pathway of zebrafish ionocyte development $[45,50])$. It is interesting to compare the current zebrafish model (Fig. 3) with the recently proposed model for mammalian intercalated cell differentiation [2]. Both development of zebrafish ionocytes and mammalian intercalated cells appear to involve similar signaling (i.e., the forkhead transcription factors and Notch), and the zebrafish model may provide leads to enhance our understanding of cell specification and differentiation in the mammalian kidney. Zebrafish ionocytes, which are located in external organs, skin, or gills, are easily traced during differentiation, and the function of each cell subtype can be readily investigated. As mentioned above, zebrafish possess several advantages, including ease of gene manipulation and transgenic line generation. Taken together, zebrafish ionocytes may be a highly suitable in vivo model or research platform for studies into the physiology and development of transporting cells in mammals and other animals and may bring new insights to related fields.

\section{Functional regulation of ionocytes}

Zebrafish directly encounter hypotonic freshwater, which is dynamic in its ionic concentration and composition. In laboratory acclimation experiments, zebrafish survive and behave normally in extremely soft $\left(\left[\mathrm{Na}^{+}\right]=0.03-0.1 \mathrm{mM}\right.$, $\left.\left[\mathrm{Cl}^{-}\right]=0.03-0.04 \mathrm{mM},\left[\mathrm{Ca}^{2+}\right]=0.02-0.05 \mathrm{mM}\right)[10,17,20$, $111,119]$, acidic $(\mathrm{pH} 4)$ or alkaline ( $\mathrm{pH} \mathrm{10)}$ waters [43], and water containing high ammonia $\left(5 \mathrm{mM} \mathrm{NH}_{4}^{+}\right)$[92]. Environmental changes directly disturb zebrafish body fluid ionic/osmotic homeostasis, and zebrafish have to quickly and effectively regulate their transepithelial ion transport functions to make compensatory adjustments. These regulatory processes include (1) a prompt adjustment, on the scale of minutes to hours, of pre-existing transporters or ionocytes and (2) long-term regulation, on the scale of hours to days, of transporter expression and ionocyte number and thus overall functional capacity. In a live medaka embryo, sequential and real-time probing of the same ionocytes in the skin revealed that a functional change from inward $\mathrm{Na}^{+} / \mathrm{Cl}^{-}$currents $(\mathrm{NaCl}$ uptake) to outward currents $(\mathrm{NaCl}$ secretion) was achieved within $2 \sim 5 \mathrm{~h}$ of the transfer from freshwater to seawater [91]. Similarly, the apical surface structure (labeled with ConA, a membrane marker) and $\mathrm{H}^{+}$ activity (measured by SIET) within the HR ionocytes of zebrafish embryos were modulated within 10 120 min of acute transfer from $\mathrm{pH} 7$ to $\mathrm{pH} 4$ [52]. These rapid regulatory responses may be mediated by the trafficking of HA molecules in HR cells, as for intercalated cells of the mammalian kidney [12]. A recent study on zebrafish micro(mi) RNA 8 [31] shed further light on this issue. Nherf1, a regulator of apical trafficking of ion transporters, was found to be associated with $\mathrm{Na}^{+}$uptake in zebrafish HR cells, and miRNA 8 was demonstrated to regulate Nherf1 expression and apical membrane trafficking/clustering (monitored by ConA staining) and thus $\mathrm{Na}^{+}$uptake (sodium green accumulation) [31].

Acclimation to ion $\left(\mathrm{Ca}^{2+}, \mathrm{Na}^{+}\right.$, or $\left.\mathrm{Cl}^{-}\right)$deficient, high $\mathrm{NH}_{4}{ }^{+}$, or acidic freshwater for several days to 2 weeks has been reported to result in increased expression of genes encoding related ion transporters $[8,20,43,76$, $85,92,119]$ and increased numbers of ionocytes in zebrafish embryos or adult gills [14, 43, 85]. A recent study further explored the cellular events associated with these regulatory processes [43]. A 4-day acclimation to $\mathrm{pH} 4$ freshwater induced a compensatory enhancement in acid secretion by zebrafish embryos, and 
Fig. 3 Model of the differentiation pathways of zebrafish skin ionocytes. A detailed explanation of the pathways is given in the text ("Proliferation and differentiation of ionocytes" section). NaR $\mathrm{Na}^{+}-\mathrm{K}^{+}$-ATPase-rich, $H R \mathrm{H}^{+}$-ATPase-rich
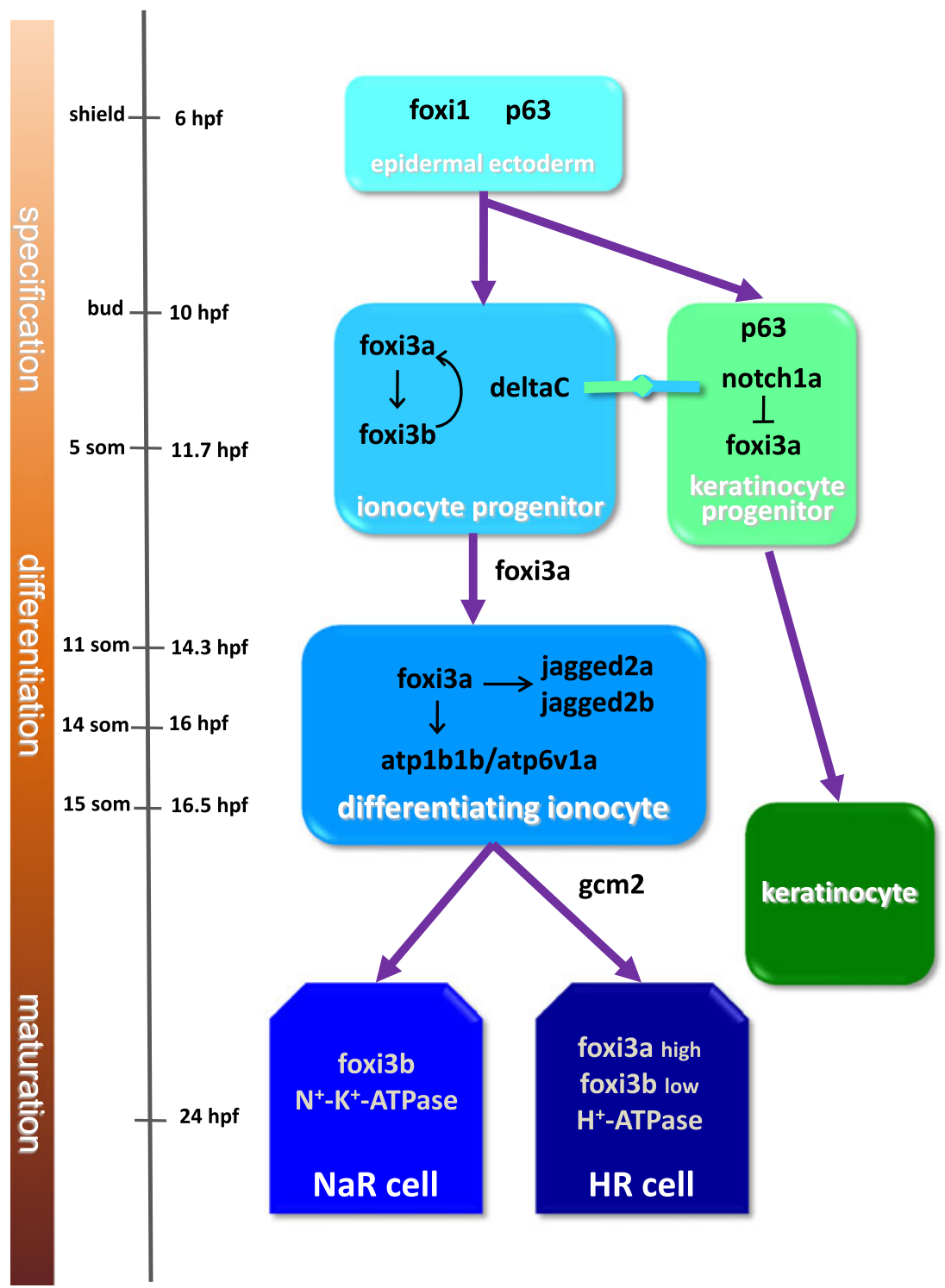

this functional enhancement of HR cells was achieved not only by increasing the cell number but also by increasing the acid-secreting function (as measured by SIET) of single cells [43]. Further labeling experiments demonstrated that additional HR cells in $\mathrm{pH} 4$ water originated from differentiation of both ionocyte precursor cells and newly proliferating epithelial stem cells [43], and loss-of-function experiments revealed that such differentiation was stimulated by $\mathrm{Gcm} 2$ [14].

\section{Hormonal control of ion regulation}

Hormones are known to tightly control the ionic homeostasis of body fluid, and many of the functions and actions of hormones on ion regulation are common to all vertebrates [80]. Here, we summarize recent findings on the hormonal control of ion regulation in zebrafish.
Regulation of $\mathrm{Ca}^{2+}$ uptake

Different hormones participate in the control and regulation of $\mathrm{Ca}^{2+}$ homeostasis [44]. To date, seven hormones have been proposed to be involved in $\mathrm{Ca}^{2+}$ regulation in zebrafish, namely prolactin (PRL), growth hormone (GH), parathyroid hormone (PTH1), cortisol, vitamin $\mathrm{D}$, calcitonin (CT), and stanniocalcin (STC-1) [44, 47, 70, 77, 78, 104]. These hormones exhibit both positive and negative regulatory actions through complicated network acting on body fluid $\mathrm{Ca}^{2+}$ homeostasis in zebrafish. In zebrafish embryos, transcription of the genes encoding PRL, GH, and PTH1 was stimulated upon acclimation to $1 / 20 \times$ diluted freshwater (34 40 $\mu \mathrm{M} \mathrm{NaCl}, 0.8 \mu \mathrm{M} \mathrm{Ca}^{2+}$ ), and transcription returned to the original levels observed in normal freshwater $\left(680 \sim 800 \mu \mathrm{M} \mathrm{NaCl}, 16 \mu \mathrm{M} \mathrm{Ca}^{2+}\right)$ if the $1 / 20 \times$ freshwater was supplemented with $16 \mu \mathrm{M} \mathrm{CaCl}_{2}$; this suggests that the affected hormones have roles in $\mathrm{Ca}^{2+}$ homeostasis and bone 
formation [44]. PRL and GH are well-known as freshwateracclimation- and seawater-acclimation hormones, respectively $[28,80]$. However, the exact role of GH in body fluid ionic homeostasis in zebrafish, a stenohaline freshwater species, is unknown. Similar to its mammalian counterpart, zebrafish PTH appears to be a regulator of $\mathrm{Ca}^{2+}$ homeostasis, although teleosts lack anatomically distinct parathyroid glands [115]. A role for zebrafish PTH in $\mathrm{Ca}^{2+}$ homeostasis has been supported by several recent studies (see below).

The recently established model for the roles of zebrafish $\mathrm{Ca}^{2+}$-transporting ionocytes (see " $\mathrm{Na}^{+}-\mathrm{K}^{+}$-ATPase-rich ionocytes" section) provides a competent platform to precisely study the target ion transporters of $\mathrm{Ca}^{2+}$ regulatory hormones. Several hormones are proposed to regulate $\mathrm{ECaC}$ expression to control body fluid $\mathrm{Ca}^{2+}$ homeostasis. Acclimation to low- $\mathrm{Ca}^{2+}$ freshwater was reported to stimulate $\mathrm{Ca}^{2+}$ influx and expression of $\mathrm{ECaC}, 11 \beta$-hydroxylase, and the glucocorticoid receptor (GR) [78]. Exogenous cortisol was found to increase $\mathrm{Ca}^{2+}$ influx and expression of $\mathrm{ECaC}$ and hydroxysteroid 11-beta dehydrogenase 2; expression of 11b-hydroxylase and the GR, however, was decreased, and other $\mathrm{Ca}^{2+}$ transporters (PMCA and $\mathrm{NCX}$ ) and the mineralocorticoid receptor (MR) were unaffected [78]. These findings suggest an involvement of cortisol-GR signaling in the stimulation of $\mathrm{Ca}^{2+}$ uptake. This hypothesis was further supported by loss-of-function experiments; morpholino knockdown of the GR, but not the MR, impaired zebrafish $\mathrm{Ca}^{2+}$ uptake function by inhibiting $\mathrm{ECaC}$ expression [78]. In mammals, both glucocorticoids and mineralocorticoids are involved in regulating body fluid osmolality and ion levels $[16,81]$. Glucocorticoids decrease body fluid $\mathrm{Ca}^{2+}$ levels through suppressing the TRPV6 and calbindin- $\mathrm{D}_{9} \mathrm{~K}$ in the kidney and duodenum $[48,64]$. Due to a lack of aldosterone synthase, cortisol is the main corticosteroid in fish $[6,84]$. Cortisol can bind to both the GR and $\mathrm{MR}$, albeit with different affinities, and each signaling pathway has different effects on the transcription of genes encoding ion transporters in the gills [63]. The different effects of cortisol on $\mathrm{Ca}^{2+}$ regulation in mammals and fish may reflect the differences in the $\mathrm{Ca}^{2+}$ absorption pathways between terrestrial and aquatic vertebrates. On the other hand, a recent study used a heterologous antibody to reveal that GR is not localized to zebrafish NaR cells (the ionocytes responsible for $\mathrm{Ca}^{2+}$ absorption, see " $\mathrm{Na}^{+}-\mathrm{K}^{+}$ATPase-rich ionocytes" section), questioning about the role of cortisol in zebrafish $\mathrm{Ca}^{2+}$ uptake [66]. The in situ hybridization with a specific GR RNA probe, however, demonstrated the presence of GR mRNA in NaR and other types of cell in the zebrafish gill [78]. Subtle differences between the methodologies or antibody specificity may be responsible for this inconsistency, but this awaits confirmation.

Bioactive vitamin D is well-documented as a vital hormone regulating $\mathrm{Ca}^{2+}$ uptake in mammals. Complexes of vitamin $\mathrm{D}_{3}$ and the vitamin $\mathrm{D}$ receptor (VDR) can upregulate mammalian $\mathrm{ECaC}$ translation by binding to the VDR responsive element (VDRE) of $\mathrm{ECaC}$ and thereby enhance $\mathrm{Ca}^{2+}$ absorption [40]; this is consequently an important pathway for the control of $\mathrm{Ca}^{2+}$ homeostasis in mammals. The zebrafish ECaC also possesses putative VDREs; however, the target cells or transporters of vitamin D-VDR signaling in fish teleosts were unknown until recently [77]. As for exogenous cortisol, exogenous vitamin D was also reported to increase $\mathrm{Ca}^{2+}$ influx and $\mathrm{ECaC}$ expression, with no effects on PMCA and NCX; furthermore, exogenous vitamin D increased 25-hydroxyvitamin $D_{3}-24-$ hydroxylase expression but decreased $1 \alpha$-hydroxylase (cyp27b1) expression. Vitamin D-mediated enhancement of $\mathrm{ECaC}$ expression/function was found to occur through interaction with only one of the duplicate VDRs in zebrafish (VDRa), based on loss-of-function analyses of the two receptors [77]. In addition, exogenous cortisol treatment stimulated, while knockdown of the GR (but not the MR) suppressed transcription of the genes encoding VDRa, cyp27a1 and cyp27b1, indicating that cortisol-mediated increases in $\mathrm{ECaC}$ expression enhance $\mathrm{Ca}^{2+}$ uptake via GR and vitamin D signaling [77, 78].

In addition to calciotropic hormones, hypocalcemic hormones are also involved in the regulation of $\mathrm{Ca}^{2+}$ uptake. STC-1 is secreted from the corpuscles of Stannius that are attached to the kidney. Surgical removal of the corpuscles of Stannius causes hypercalcemia, suggesting a hypocalcemic function of STC-1. In zebrafish embryos, high-/low-Ca ${ }^{2+}$ acclimation experiments and loss-/gain-of-function experiments revealed that STC-1 reduces $\mathrm{Ca}^{2+}$ uptake in response to excess $\mathrm{Ca}^{2+}$ in the body by negatively regulating $\mathrm{ECaC}$ expression [104]. Human STC-1 also exhibits antihypercalcemic actions [108]. Mammalian STC-1 decreases $\mathrm{Ca}^{2+}$ uptake across the intestines and kidney [110, 121], which presumably also occurs through decreased ECaC expression. The signal pathways underlying STC-1mediated inhibition of $\mathrm{ECaC}$ expression in both mammals and fish remain unknown, due to a lack of information on the STC-1 receptor. Discovery and characterization of the STC-1 receptor are required to further elucidate the roles of STC-1. As regards the regulation of STC-1, a recent study utilized a forward genetic mutagenesis screen and positional cloning to identify macrophage-stimulating protein (Msp), as a novel $\mathrm{Ca}^{2+}$ homeostasis modulator that may act upstream of zebrafish STC-1 [47]. In situ hybridization of the receptor for Msp, Ron, revealed the specific expression in the corpuscles of Stannius; Ron knockdown morphants and $m s p$ mutant embryos presented with identical phenotypes, which could be rescued by excess $\mathrm{Ca}^{2+}$ [47]. The $m s p$ mutant embryos had higher levels of STC-1, ECaC, PTH1, and PTH2 expression and elevated body $\mathrm{Ca}^{2+}$ content as compared to wild-type embryos [47]. These results suggest that the 
Msp/Ron signaling pathway controls $\mathrm{Ca}^{2+}$ homeostasis, most likely through interactions with other hormones, such as STC1 and PTH1.

$\mathrm{CT}$ is another hypocalcemic hormone in zebrafish and mammals. Zebrafish embryos treated with high- $\mathrm{Ca}^{2+}$ water was found to upregulate expression of $\mathrm{CT}$ and its receptor (CTR), but downregulate expression of $\mathrm{ECaC}$ [70]. Knockdown of $\mathrm{CT}$ stimulated $\mathrm{ECaC}$ expression and suppressed $\mathrm{CTR}$, while overexpression of $\mathrm{CT}$ inhibited $\mathrm{ECaC}$ expression in zebrafish embryos incubated in high- $\mathrm{Ca}^{2+}$ freshwater, supporting an anti-hypercalcemic role for CT [70]. In mammals, CT appears to inhibit intestinal $\mathrm{Ca}^{2+}$ absorption and renal $\mathrm{Ca}^{2+}$ reabsorption [62], but this function remains controversial. Microperfusion experiments in rabbits demonstrated that CT stimulates $\mathrm{Ca}^{2+}$ absorption in distal convoluted tubules where TRPV5 is not expressed [94]. Injection of $\mathrm{CT}$ into mice also stimulated renal $\mathrm{Ca}^{2+}$ reabsorption without affecting TRPV5 expression, and similar effects were observed in TRPV5 $5^{-}$mice, suggesting that the CT acts independently of TRPV in renal $\mathrm{Ca}^{2+}$ reabsorption [46].

$\mathrm{ECaC}$ appears to be the primary target in hormonemediated regulation of epithelial $\mathrm{Ca}^{2+}$ transport, as the other $\mathrm{Ca}^{2+}$ transporters, PMCA and NCX, are apparently unaffected. However, basolateral PMCA and NCX may still be targeted by regulatory mechanisms under some conditions. For example, overexpression of $\mathrm{CT}$ suppressed $\mathrm{ECaC}$ and stimulated STC-1 expression in zebrafish embryos at $30 \mathrm{hpf}$ but upregulated expression of several hypercalcemic factors (including PMCA2, NCX1, PTH receptors (PTH1R, PTH2R, and PTH3R), and VDR) at 4 days post-fertilization [70]. These results suggest biphasic effects of CT; a CT-mediated decrease of $\mathrm{Ca}^{2+}$ uptake results in short-term hypocalcemia; this may activate hypercalcemic signaling, which would compensate for the $\mathrm{Ca}^{2+}$ imbalance through hypercalcemic hormones and other $\mathrm{Ca}^{2+}$ transporters. This highlights the importance of hormone interactions on $\mathrm{Ca}^{2+}$ homeostasis in zebrafish and mammals.

\section{Regulation of $\mathrm{Na}^{+}$uptake}

Cortisol was also found to play roles in regulating $\mathrm{Na}^{+}$ uptake in zebrafish. Treatment with exogenous cortisol was found to increase $\mathrm{Na}^{+}$uptake in zebrafish embryos, and this enhancement was blocked by a selective GR antagonist, RU-486 [66]. In contrast, treatment with aldosterone, a selective agonist for MR, had no effect on $\mathrm{Na}^{+}$uptake, suggesting that cortisol increases $\mathrm{Na}^{+}$uptake via GR, but not MR signaling [66]. Supporting these pharmacological data, loss-of-function experiments indicated that $\mathrm{Na}^{+}$uptake was not induced under acidic environments in GR morphants [66]. Overall, it seems that cortisol-GR, but not cortisol-MR, signaling is involved in the regulation of $\mathrm{Na}^{+}$ in zebrafish acclimated to acidic environment [66], although some debates remain. GR loss-of-function experiments did not affect $\mathrm{Na}^{+}$uptake in zebrafish reared in normal freshwater [66], conflicting with another study demonstrating the role of cortisol-GR signaling in differentiation of all the types of zebrafish ionocytes [21]. In the study by Cruz et al. [21], the same GR morpholinos was found to suppress the differentiation of HR cells (and other types of ionocytes), and a resultant impairment in $\mathrm{Na}^{+}$uptake in zebrafish is conceivably predicted. This discrepancy needs further clarification in the future.

Neurohormones such as catecholamines also contribute to $\mathrm{Na}^{+}$uptake in zebrafish. In additional to their role in vasoactive regulation, epinephrine/norepinephrine is known to directly affect gill ionic transport via inhibition by $\alpha$ adrenergic receptors and stimulation by $\beta$ receptors (for a detailed review, see [28]). This reverse or biphasic control of $\alpha$ - and $\beta$-adrenergic receptors in fish ion regulation was reconfirmed in zebrafish through pharmacological and lossof-function approaches [69]. Pharmacological screening was performed to identify $\alpha$ - and $\beta$-adrenergic receptors with inhibitory and stimulatory roles, respectively, on $\mathrm{Na}^{+}$ uptake in zebrafish embryos [69]. $\beta$ receptor loss of function impaired $\mathrm{Na}^{+}$uptake only under acidic or ion poor environment, suggesting that $\mathrm{Na}^{+}$uptake in zebrafish is regulated via adrenergic receptors [69]. In support of this hypothesis, it was found that HR cells can be labeled with fluorescent propranolol (a $\beta$ receptor antagonist) and zn-12 (a genetic neuronal marker) [69]. These findings further argue for $\beta$-adrenergic regulation of ion transport function in fish gill ionocytes but also raise several questions. Treatment of zebrafish embryos with exogenous epinephrine was reported to suppress $\mathrm{Na}^{+}$uptake, while norepinephrine treatment stimulated $\mathrm{Na}^{+}$uptake; this surprising result was attributed to different affinities to the receptors [69]. As in mammals, epinephrine and norepinephrine reach their target tissues (including the gills and skin) in teleosts via both neurotransmission from local sympathetic innervation and by systematic stimulation of chromaffin cells [28]. In mammals, sympathetic nerves participate via $\alpha$ - and $\beta$ adrenergic receptors in the complicated regulatory network of several kidney functions associated with body fluid ionic homeostasis [22], and catecholamines and other hormones (including vasopressin, parathyroid, glucagon, and angiotensin II) regulate renal $\mathrm{NaCl}$ transport through complex interactions [3, 7]. The conflicting data in zebrafish may perhaps be resolved by taking the interactions between systematic and local catecholamines, different adrenergic receptors, and other hormones, into consideration.

In mammals, renal sympathetic activity induced by $\beta$ adrenergic receptor stimulation activates the $\mathrm{Na}^{+}-\mathrm{K}^{+}-2 \mathrm{Cl}^{-}$ cotransporter II, NCC, and pendrin [3, 5, 82]. Both HR and $\mathrm{NaR}$ ionocytes in zebrafish are innervated by nerve fibers 
(with zn-12 as a marker; [57, 69]). This raises the possibility that neurohormones may control the transport functions of not only $\mathrm{Na}^{+}$, but also other ions, through regulating various transporters in zebrafish; however, $\mathrm{Na}^{+}$uptake in zebrafish is reportedly unaffected by serotonin and dopamine [69].

\section{Regulation of other transport functions}

Pituitary hormone PRL has long been known to play a major role in hyper-osmoregulation in freshwater teleosts [28]. To understand the role of osmotic homeostasis in the development of PRL-secreting lactotrophs, Liu et al. [79] generated germline transgenic zebrafish expressing red fluorescent protein under the control of PRL regulatory elements (PRL-RFP). They reported that environmental osmotic changes (0.025 1.0\% of salt concentration) affected PRL cell proliferation in a dopamine-independent manner [79]. The osmotic response in PRL cells was abolished by knockdown of the PRL receptor, and over-expression of PRL decreased the PRL cell mass, suggesting that osmotic feedback on PRL cells is mediated by PRL signaling via the PRL receptor in the pituitary [79]. Other hormones such as atrial natriuretic peptide (ANP) and renin have also been reported to participate in ion regulation in zebrafish. Transcription of the genes encoding ANP and renin in zebrafish embryos was increased in $1 / 20 \times(34 \sim 40 \mu \mathrm{M} \mathrm{NaCl})$ freshwater and decreased in $100 \times(68 \sim 80 \mathrm{mM} \mathrm{NaCl})$ freshwater [39]. Zebrafish embryos raised in $1 / 20 \times$ freshwater supplemented with $680 \sim 690 \mu \mathrm{M} \mathrm{NaCl}$ presented with severe edema (i.e., hypervolemia) and increased ANP expression (renin expression was unaffected), as compared with those raised in $1 / 20 \times$ freshwater, suggesting that ANP and renin are the volume-regulating and $\mathrm{Na}^{+}$-regulating hormones during freshwater adaptation, respectively [44]. Consequently, PRL/PRL receptor, ANP, and renin were proposed to regulate transport of $\mathrm{NaCl}$ and/or other ions in zebrafish during acclimation to freshwater with various ionic compositions [44, 79]. The ionocyte types, transporters, and ions affected by these hormones, and the exact nature of the regulatory mechanisms, remain unknown. The establishment of zebrafish as a model for the identification, functional analysis, and differentiation of ionocytes means there has never been a better time to explore these issues.

Regulation of the proliferation and differentiation of ionocytes

Ionocyte function can be regulated at the level of ionocyte proliferation and differentiation, and hormones are involved at this step. Our understanding of the role of isotocinneurophysin (Itnp; a homolog of mammalian oxytocin) in fish osmoregulation is limited to the findings of a very few studies into the effects of environmental salinity on isotocin expression and secretion [53, 112]. A recent study in zebrafish demonstrated that isotocin activates the genetic operons for ionocyte progenitor proliferation and differentiation, via transcriptional and translational pathways [19]. Exposing zebrafish embryos to conditions which disturb the body fluid ionic balance (thus triggering a compensatory increase of ionocyte function) was found to increase transcription of the isotocin gene. Further loss- and gain-offunction experiments indicated that Itnp enhances epidermal stem cell proliferation and facilitates ionocyte differentiation by enhancing transcription of Foxi3a [19]. As such, zebrafish isotocin may increase ionocyte density through stimulation of cell proliferation/differentiation, ultimately regulating ionocyte function. On the other hand, the primary mode of action of cortisol on fish ion regulation was proposed to be cytogenic, through mediating the growth and differentiation of ionocytes in the gill epithelium [28]. This hypothesis lacks convincing support because the molecular pathways of proliferation/differentiation of fish ionocytes were unknown until they were recently elucidated in zebrafish (see "Proliferation and differentiation of ionocytes" section). Exogenous cortisol treatment of zebrafish embryos caused a dose-dependent increase in the densities of ionocyte progenitors and mature ionocytes $(\mathrm{NaR}$ and HR cells), but had no effect on p63-expressing epidermal stem cells [21]. Cortisol also increased the number of ionocytes in cultured adult zebrafish gills, and this was accompanied by increased expression of Foxi3a/3b; this indicates that cortisol controls ionocyte function by stimulating differentiation of ionocytes, but not epidermal stem cells [21].

In mammals, oxytocin was found to be involved in cell growth and differentiation in many tissues, including heart [34], bone [101], and mammary gland [89]; however, there is no evidence to suggest that oxytocin participates in the differentiation of kidney cells. Oxytocin regulates body fluid homeostasis by stimulating water uptake and simultaneously reducing $\mathrm{Na}^{+}$reabsorption, which consequently results in a decrease in body fluid osmolarity [38]. Similar to oxytocin, cortisol has also been suggested to be a growth and cell differentiation factor [60, 120]. Moreover, dexamethasone (a synthetic glucocorticoid) was found to increase the mRNA and protein of many ion transporters, including $\mathrm{NHE} 3, \mathrm{NKCC}, \mathrm{NCC}$, and $\mathrm{ENaC}$, in rat kidney [32]. In addition, aldosterone, a mineralocorticoid, contributes to normal renal cell proliferation and differentiation from stem cells, as well as to the development of pathological conditions through dysregulation of renal cell growth in the adult [103]. Taken together, it is possible that oxytocin and cortisol modulate the growth or differentiation of renal tubular cells and thereby regulate transepithelial ion and acid/base transport. Since the specification, differentiation, and patterning of ionocytes have been comprehensively elucidated in zebrafish by taking advantage of the many 
efficient genetic and molecular tools available, it should also be a suitable model for studying the hormonal control of ionocyte proliferation and differentiation. An understanding of these areas in zebrafish would not only contribute to fish physiological research but also provide insights to aid studies in mammals and other animals.

\section{Conclusions and perspectives}

HR, NaR, NCC, and KS ionocytes in zebrafish embryonic skin and gills express distinct sets of ion transporters and thus perform transepithelial $\mathrm{H}^{+}$secretion $/ \mathrm{Na}^{+}$uptake $/ \mathrm{NH}_{4}{ }^{+}$ excretion, $\mathrm{Ca}^{2+}$ uptake, $\mathrm{Na}^{+} / \mathrm{Cl}^{-}$uptake, and $\mathrm{K}^{+}$secretion, respectively. Validation of the proposed zebrafish model requires analysis of the transport kinetics and stoichiometry of several apical transporters (e.g., NCC, pendrin), to understand how these transporters operate in a hypotonic freshwater environment with thermodynamically unfavorable chemical gradients. Basolateral transporters, such as $\mathrm{ClC}$ and $\mathrm{KCC}$, await identification and functional analysis. The search for new transporters and transport functions in identified ionocytes or in new types of ionocytes is still in progress, and this may lead to the development of a more comprehensive model. In the model for the molecular pathways of ionocyte development, ionocyte progenitors develop from epidermal stem cells and then differentiate into $\mathrm{NaR}$ and HR ionocyte types through a positive regulatory loop involving Foxi3a/-3b and other transcription factors. Although more studies are required to fully elucidate these pathways, the proposed model has helped to pave the way for studies into the role of cell proliferation and differentiation in the functional regulation of ionocytes. Several hormones have been found to participate in the regulatory pathways of ionic homeostasis in zebrafish; detailed studies into the target ion transport pathways, ion transporters, or ionocytes of hormonal actions have been performed, particularly for cortisol, vitamin D, STC-1, CT, and isotocin and their specific receptors, and similar approaches could be applied to other hormones in the future.

The four types of ionocyte in zebrafish are analogous to various renal tubular cells, in terms of their ion transporter expression and function. Zebrafish is highly suited for experimental analysis, in terms of the applicability of molecular tools, ease of in vivo cellular observation and function analysis, and rapid embryonic development, and these advantages enable this model to not only enhance our understanding of body fluid ion homeostasis and hormonal control in fish but to also inform studies on mammals or other animal species, thereby providing insights into related fields. However, the drawbacks of the zebrafish model need to be taken into consideration. While pharmacological and loss-of-function approaches are comparatively easy and efficient methods with which to assay the ion regulatory roles of ion transporters, hormones, and hormone receptors in zebrafish in vivo, the necessary reagents or morpholinos affect whole zebrafish embryos; as such, interpretations of cause and effect should be made cautiously, pending further experiments to tease apart the compensatory responses of different transporters or isoforms and the effects of interactions between systemic and local hormones, different receptors, and other hormones.

Acknowledgments Our original research was financially supported by grants from the National Science Council and Academia Sinica of Taiwan, ROC. We thank Y. C. Tung for her technical and secretarial assistance.

Open Access This article is distributed under the terms of the Creative Commons Attribution License which permits any use, distribution, and reproduction in any medium, provided the original author(s) and the source are credited.

\section{References}

1. Abbas L, Hajihashemi S, Stead LF, Cooper GJ, Ware TL, Munsey TS, Whitfield TT, White SJ (2011) Functional and developmental expression of a zebrafish Kir1.1 (ROMK) potassium channel homologue Kcnj1. J Physiol 589:1489-1503

2. Al-Awqati Q, Gao XB (2011) Differentiation of intercalated cells in the kidney. Physiol 26:266-272

3. Ares GR, Caceres PS, Ortiz PA (2011) Molecular regulation of NKCC2 in the thick ascending limb. Am J Physiol Renal Physiol 301:F1143-F1159

4. Avella M, Bornancin M (1989) A new analysis of ammonia and sodium transport through the gills of the freshwater rainbow trout (Salmo gairdneri). J Exp Biol 142:155-175

5. Azroyan A, Morla L, Crambert G, Laghmani K, Ramakrishnan S, Edwards A, Doucet A (2012) Regulation of pendrin by cAMP: possible involvement in beta-adrenergic-dependent $\mathrm{NaCl}$ retention. Am J Physiol Renal physiol 302:F1180-F1187

6. Baker ME (2003) Evolution of glucocorticoid and mineralocorticoid responses: go fish. Endocrinology 144:4223-4225

7. Baum M (2010) Effect of catecholamines on rat medullary thick ascending limb chloride transport: interaction with angiotensin II. Am J Physiol Regul Integr Comp Physiol 298:R954-R958

8. Bayaa MB, Vulesevic A, Esbaugh M, Braun ME, Ekker M, Perry SF (2009) The involvement of SLC26 anion transporters in chloride uptake in zebrafish (Danio rerio) larvae. J Exp Biol 212:3283-3295

9. Blomqvist SR, Vidarsson H, Fitzgerald S, Johansson BR, Ollerstam A, Brown R, Persson AE, Bergstrom GG, Enerback S (2004) Distal renal tubular acidosis in mice that lack the forkhead transcription factor Foxi1. J Clin Invest 113:1560-1570

10. Boisen AM, Amstrup J, Novak I, Grosell M (2003) Sodium and chloride transport in soft water and hard water acclimated zebrafish (Danio rerio). Biochim Biophys Acta 1618:207-218

11. Braun MH, Steele SL, Ekker M, Perry SF (2009) Nitrogen excretion in developing zebrafish (Danio rerio): a role for $\mathrm{Rh}$ proteins and urea transporters. Am J Physiol Renal Physiol 296:F994-F1005

12. Brown D, Paunescu TG, Breton S, Marshansky V (2009) Regulation of the V-ATPase in kidney epithelial cells: dual role in acid/base homeostasis and vesicle trafficking. J Exp Biol 212:1762-1772

13. Carraro-Lacroix LR, Malnic G (2010) Acid-base transport by the renal distal nephron. J Nephrol 23:S19-S27 
14. Chang WJ, Horng JL, Yan JJ, Hsiao CD, Hwang PP (2009) The transcription factor, glial cell missing 2 , is involved in differentiation and functional regulation of $\mathrm{H}^{+}$-ATPase-rich cells in zebrafish (Danio rerio). Am J Physiol Regul Integr Comp Physiol 296(4):R1192-R1201

15. Chang WJ, Hwang PP (2011) Development of zebrafish epidermis. Birth Defects Res C 93:205-214

16. Charmandari E, Tsigos C, Chrousos G (2005) Endocrinology of the stress response. Annu Rev Physiol 67:259-284

17. Chen YY, Lu FI, Hwang PP (2003) Comparisons of calcium regulation in fish larvae. J Exp Zool 295A:127-135

18. Chou MY, Hsiao CD, Chen SC, Chen IW, Liu ST, Hwang PP (2008) Effects of hypothermia on gene expression in zebrafish gills: upregulation in differentiation and function of ionocytes as compensatory responses. J Exp Biol 211:3077-3084

19. Chou MY, Hung JC, Wu LC, Hwang SP, Hwang PP (2011) Isotocin controls ion regulation through regulating ionocyte progenitor differentiation and proliferation. Cell Mol Life Sci 68:2797-2809

20. Craig PM, Wood CM, McClelland GB (2007) Gill membrane remodeling with soft-water acclimation in zebrafish (Danio rerio). Physiol Genomics 30:53-60

21. Cruz SA, Chao PL, Hwang PP (2013) Cortisol promotes differentiation of epidermal ionocytes through Foxi3 transcription factors in zebrafish (Danio rerio). Comp Biochem Physiol A Mol Integr Physiol 164:249-257

22. DiBona GF (2005) Physiology in perspective: the wisdom of the body. Neural control of the kidney. Am J Physiol Regul Integr Comp Physiol 289:R633-R641

23. Dymowska A, Hwang PP, Goss GG (2012) Structure and function of ionocytes in the freshwater fish gill. Respir Physiol Neurobiol 184:249-257

24. Esaki M, Hoshijima K, Kobayashi S, Fukuda H, Kawakami K, Hirose S (2007) Visualization in zebrafish larvae of $\mathrm{Na}^{+}$uptake in mitochondria-rich cells whose differentiation is dependent on foxi3a. Am J Physiol Regul Integr Comp Physiol 292:R470-R480

25. Esaki M, Hoshijima K, Nakamura N, Munakata K, Tanaka M, Ookata K, Asakawa K, Kawakami K, Wang W, Weinberg ES, Hirose S (2009) Mechanism of development of ionocytes rich in vacuolar-type $\mathrm{H}^{+}$-ATPase in the skin of zebrafish larvae. Dev Biol 329:116-129

26. Evans DH (2008) Teleost fish osmoregulation: what have we learned since August Krogh, Homer Smith, and Ancel Keys. Am J Physiol Am J Physiol Regul Integr Comp Physiol 295: R704-R713

27. Evans DH (2011) Freshwater fish gill ion transport: august Krogh to morpholinos and microprobes. Acta Physiol 202:349-359

28. Evans DH, Piermarini PM, Choe KP (2005) The multifunctional fish gill: dominant site of gas exchange, osmoregulation, acidbase regulation, and excretion of nitrogenous waste. Physiol Rev 85:97-177

29. Flik G, Kaneko T, Greco AM, Li J, Fenwick JC (1997) Sodium dependent ion transporters in trout gills. Fish Physiol Biochem $17: 385-396$

30. Flik G, Verbost PM, Wendelaar Bongar SE (1995) Calcium transport process in fishes. In: Wood CM, Shuttleworth TJ (eds) Cellular and molecular approaches to fish ionic regulation. Academic, San Diego, pp 317-342

31. Flynt AS, Thatcher EJ, Burkewitz K, Li N, Liu Y, Patton JG (2009) miR-8 microRNAs regulate the response to osmotic stress in zebrafish embryos. J Cell Biol 185:115-127

32. Frindt G, Palmer LG (2012) Regulation of epithelial Na+ channels by adrenal steroids: mineralocorticoid and glucocorticoid effects. Am J Physiol Renal Physiol 302:F20-F26

33. Gao X, Eladari D, Leviel F, Tew BY, Miro-Julia C, Cheema F, Miller L, Nelson R, Paunescu TG, McKee M et al (2010)
Deletion of hensin/DMBT1 blocks conversion of beta- to alphaintercalated cells and induces distal renal tubular acidosis. Proc Natl Acad Sci USA 107:21872-21877

34. Gassanov N, Devost D, Danalache B, Noiseux N, Jankowski M, Zingg HH, Gutkowska J (2008) Functional activity of the carboxyl-terminally extended oxytocin precursor Peptide during cardiac differentiation of embryonic stem cells. Stem Cells 26:45-54

35. Gilmour KM (2012) New insights into the many functions of carbonic anhydrase in fish gills. Respir Physiol Neurobiol 184:223-230

36. Glover M, Zuber AM, O'Shaughnessy KM (2011) Hypertension, dietary salt intake, and the role of the thiazide-sensitive sodium chloride transporter NCCT. Cardiovasc Ther 29:68-76

37. Good DW, Velazquez H, Wright FS (1984) Luminal influences on potassium secretion: low sodium concentration. Am J Physiol Renal Fluid Electrolyte Physiol 246:F609-F619

38. Haanwinckel MA, Elias LK, Favaretto AL, Gutkowska J, McCann SM, Antunes-Rodrigues J (1995) Oxytocin mediates atrial natriuretic peptide release and natriuresis after volume expansion in the rat. Proc Natl Acad Sci USA 92:7902-7906

39. Hibino H, Inanobe A, Furutani K, Murakami S, Findlay I, Kurachi Y (2010) Inwardly rectifying potassium channels: their structure, function, and physiological roles. Physiol Rev 90:291-366

40. Hoenderop JG, Nilius B, Bindels RJ (2005) Calcium absorption across epithelia. Physiol Rev 85:373-422

41. Horng JL, Hawng PP, Shin TH, Wen ZH, Lin CS, Lin LY (2009) Chloride transport in mitochondrion-rich cells of euryhaline tilapia (Oreochromis mossambicus) larvae. Am J Physiol Cell Physiol 297:C845-C854

42. Horng JL, Lin LY, Huang CJ, Katoh F, Kaneko T, Hwang PP (2007) Knockdown of V-ATPase subunit A (atp6vla) impairs acid secretion and ion balance in zebrafish (Danio rerio). Am Am J Physiol Regul Integr Comp Physiol 292:R2068-R2076

43. Horng JL, Lin LY, Hwang PP (2009) Functional regulation of $\mathrm{H}^{+}$ATPase-rich cells in zebrafish embryos acclimated to an acidic environment. Am J Physiol Cell physiol 296:C682-C692

44. Hoshijima K, Hirose S (2007) Expression of endocrine genes in zebrafish larvae in response to environmental salinity. J Endocrinol 193:481-491

45. Hsiao CD, You MS, Guh YJ, Ma M, Jiang YJ, Hwang PP (2007) A positive regulatory loop between foxi3a and foxi3b is essential for specification and differentiation of zebrafish epidermal ionocytes. PLoS One 2:e302

46. Hsu YJ, Dimke H, Hoenderop JGJ, Bindels RM (2010) Calcitonin-stimulated renal $\mathrm{Ca}^{2+}$ reabsorption occurs independently of TRPV5. Nephrol Dial Transplant 25:1428-1435

47. Huitema LF, Renn J, Logister I, Gray JK, Waltz SE, Flik G, Schulte-Merker S (2012) Macrophage-stimulating protein and calcium homeostasis in zebrafish. FASEB J 26:4092-4101

48. Huybers S, Naber TH, Bindels RJ, Hoenderop JG (2007) Prednisolone-induced $\mathrm{Ca}^{2+}$ malabsorption is caused by diminished expression of the epithelial $\mathrm{Ca}^{2+}$ channel TRPV6. Am J Physiol Gastrointest Liver Physiol 292:G92-G97

49. Hwang PP (2009) Ion uptake and acid secretion in zebrafish (Danio rerio). J Exp Biol 212:1745-1752

50. Hwang PP, Lee TH (2007) New insights into fish ion regulation and mitochondrion-rich cells. Comp Biochem Physiol A Mol Integr Physiol 148:479-497

51. Hwang PP, Lee TH, Lin LY (2011) Ion regulation in fish gills: recent progress in the cellular and molecular mechanisms. Am J Physiol Regul Integr Comp Physiol 301:R28-R47

52. Hwang PP, Perry SF (2010) Ionic and acid-base regulation. In: Perry SF, Ekker M, Farrell AP, Brauner CJ (eds) Fish physiology Vol. 29. Zebrafish. Academic, San Diego, pp 311-343 
53. Hyodo S, Tsukada T, Takei Y (2004) Neurohypophysial hormones of dogfish, Triakis scyllium: structures and salinitydependent secretion. Gen Comp Endocrinol 138:97-104

54. Janicke M, Carney TJ, Hammerschmidt M (2007) Foxi3 transcription factors and Notch signaling control the formation of skin ionocytes from epidermal precursors of the zebrafish embryo. Dev Biol 307:258-271

55. Javelle A, Lupo D, Ripoche P, Fulford T, Merrick M, Winkler F (2008) Substrate binding, deprotonation, and selectivity at the periplasmic entrance of the Escherichia coli ammonia channel AmtB. Proc Natl Acad Sci USA 105:5040-5045

56. Jeong HW, Jeon US, Koo BK, Kim WY, Im SK, Shin J, Cho Y, Kim J, Kong YY (2009) Inactivation of Notch signaling in the renal collecting duct causes nephrogenic diabetes insipidus in mice. J Clin Invest 119:3290-3300

57. Jonz MG, Nurse CA (2006) Epithelial mitochondria-rich cells and associated innervation in adult and developing zebrafish. J Comp Neurol 497:817-832

58. Jouret F, Auzanneau C, Debaix H, Wada GH, Pretto C, Marbaix E, Karet FE, Courtoy PJ, Devuyst O (2005) Ubiquitous and kidney-specific subunits of vacuolar $\mathrm{H}^{+}$-ATPase are differentially expressed during nephrogenesis. J Am Soc Nephrol 16:3235-3246

59. Kahloon MU, Aslam AK, Aslam AF, Wilbur SL, Vasavada BC, Khan IA (2005) Hyperkalemia induced failure of atrial and ventricular pacemaker capture. Int J Cardiol 105:224-226

60. Karlan BY, Amin W, Casper SE, Littlefield BA (1988) Hormonal regulation of CA125 tumor marker expression in human ovarian carcinoma cells: inhibition by glucocorticoids. Cancer Res 48:3502-3506

61. Khademi S, O'Connell J 3rd, Remis J, Robles-Colmenares Y, Miercke LJ, Stroud RM (2004) Mechanism of ammonia transport by $\mathrm{Amt} / \mathrm{MEP} / \mathrm{Rh}$ : structure of $\mathrm{AmtB}$ at $1.35 \mathrm{~A}$. Science 305:1587-1594

62. Khanal RC, Nemere I (2008) Endocrine regulation of calcium transport in epithelia. Clin Exp Pharmacol Physiol 35:1277-1287

63. Kiilerich P, Kristiansen K, Madsen SS (2007) Cortisol regulation of ion transporter mRNA in Atlantic salmon gill and the effect of salinity on the signaling pathway. J Endocrinol 194:417-427

64. Kim MH, Lee GS, Jung EM, Choi KC, Oh GT, Jeung EB (2009) Dexamethasone differentially regulates renal and duodenal calcium-processing genes in calbindin-D9k and -D28k knockout mice. Exp Physiol 94:138-151

65. Koushik SV, Wang J, Rogers R, Moskophidis D, Lambert NA, Creazzo TL, Conway SJ (2001) Targeted inactivation of the sodium-calcium exchanger (NCX1) results in the lack of a heartbeat and abnormal myofibrillar organization. FASEB $\mathrm{J}$ 15:1209-1211

66. Kumai Y, Nesan D, Vijayan MM, Perry SF (2012) Cortisol regulates $\mathrm{Na}^{+}$uptake in zebrafish, Danio rerio, larvae via the glucocorticoid receptor. Mol Cell Endocrinol 364:113-125

67. Kumai Y, Perry SF (2011) Ammonia excretion via Rhcg1 facilitates $\mathrm{Na}^{+}$uptake in larval zebrafish Danio rerio, in acidic water. Am J Physiol Regul Integr Comp Physiol 301:R1517-R1528

68. Kumai Y, Perry SF (2012) Mechanisms and regulation of $\mathrm{Na}^{+}$ uptake by freshwater fish. Respir Physiol Neurobiol 184:249-256

69. Kumai Y, Ward MA, Perry SF (2012) beta-Adrenergic regulation of $\mathrm{Na}^{+}$uptake by larval zebrafish Danio rerio in acidic and ionpoor environments. Am J Physiol Regul Integr Comp Physiol 303:R1031-R1041

70. Lafont AG, Wang YF, Chen GD, Liao BK, Tseng YC, Huang CJ, Hwang PP (2011) Involvement of calcitonin and its receptor in the control of calcium-regulating genes and calcium homeostasis in zebrafish (Danio rerio). J Bone Miner Res 26:1072-1083

71. Langenbacher AD, Dong Y, Shu X, Choi J, Nicoll DA, Goldhaber JI, Philipson KD, Chen JN (2005) Mutation in sodium-calcium exchanger 1 (NCX1) causes cardiac fibrillation in zebrafish. P Natl Acad Sci USA 102:17699-17704

72. Lee YC, Yan JJ, Cruz S, Horng JL, Hwang PP (2011) Anion exchanger $1 \mathrm{~b}$, but not sodium-bicarbonate cotransporter $1 \mathrm{~b}$, plays a role in transport functions of zebrafish $\mathrm{H}^{+}$-ATPase-rich cells. Am J Physiol Cell Physiol 300:C295-C307

73. Liao BK, Chen RD, Hwang PP (2009) Expression regulation of $\mathrm{Na}^{+}-\mathrm{K}^{+}$-ATPase alpha1-subunit subtypes in zebrafish gill ionocytes. Am J Physiol Regul Integr Comp Physiol 296: R1897-R1906

74. Liao BK, Deng AN, Chen SC, Chou MY, Hwang PP (2007) Expression and water calcium dependence of calcium transporter isoforms in zebrafish gill mitochondrion-rich cells. BMC Genomics 8:354

75. Lin LY, Horng JL, Kunkel JG, Hwang PP (2006) Proton pumprich cell secretes acid in skin of zebrafish larvae. Am J Physiol Cell Physiol 290:C371-C378

76. Lin TY, Liao BK, Horng JL, Yan JJ, Hsiao CD, Hwang PP (2008) Carbonic anhydrase 2-like a and $15 \mathrm{a}$ are involved in acid-base regulation and $\mathrm{Na}^{+}$uptake in zebrafish $\mathrm{H}^{+}$-ATPase-rich cells. Am J Physiol Cell Physiol 294:C1250-C1260

77. Lin CH, Su CH, Tseng DY, Ding FC, Hwang PP (2012) Action of vitamin $\mathrm{D}$ and the receptor, VDRa, in calcium handling in zebrafish (Danio rerio). PLoS One 7:e45650

78. Lin CH, Tsai IL, Su CH, Tseng DY, Hwang PP (2011) Reverse effect of mammalian hypocalcemic cortisol in fish: cortisol stimulates $\mathrm{Ca}^{2+}$ uptake via glucocorticoid receptor-mediated vitamin $\mathrm{D}_{3}$ metabolism. PLoS One 6:e23689

79. Liu NA, Liu Q, Wawrowsky K, Yang Z, Lin S, Melmed S (2006) Prolactin receptor signaling mediates the osmotic response of embryonic zebrafish lactotrophs. Mol Endocrinol 20:871-880

80. McCormick SD, Bradshaw D (2006) Hormonal control of salt and water balance in vertebrates. Gen Comp Endocrinol 147:3-8

81. McLaughlin F, Mackintosh J, Hayes BP, McLaren A, Uings IJ, Salmon P, Humphreys J, Meldrum E, Farrow SN (2002) Glucocorticoid-induced osteopenia in the mouse as assessed by histomorphometry, microcomputed tomography, and biochemical markers. Bone 30:924-930

82. Mu S, Shimosawa T, Ogura S, Wang H, Uetake Y, KawakamiMori F, Marumo T, Yatomi Y, Geller DS, Tanaka H et al (2011) Epigenetic modulation of the renal beta-adrenergic-WNK4 pathway in salt-sensitive hypertension. Nature medicine 17:573-580

83. Nakada T, Hoshijima K, Esaki M, Nagayoshi S, Kawakami K, Hirose S (2007) Localization of ammonia transporter Rhcg1 in mitochondrion rich cells of yolk sac, gill, and kidney of zebrafish and its ionic strength-dependent expression. Am J Physiol Regul Integr Comp Physiol 293:R1743-R1753

84. Nelson DR (2003) Comparison of P450s from human and fugu: 420 million years of vertebrate P450 evolution. Arch Biochem Biophys 409:18-24

85. Pan TC, Liao BK, Huang CJ, Lin LY, Hwang PP (2005) Epithelial $\mathrm{Ca}^{2+}$ channel expression and $\mathrm{Ca}^{2+}$ uptake in developing zebrafish. Am J Physiol Regul Integr Comp Physiol 289: R1202-R1211

86. Perry SF, Vulesevic B, Bayaa M (2009) Evidence that SLC26 anion transporters mediate branchial chloride uptake in adult zebrafish (Danio rerio). Am J Physiol Regul Integr Comp Physiol 297:R988-R997

87. Purkerson JM, Schwartz GJ (2007) The role of carbonic anhydrases in renal physiology. Kidney Int 71:103-115

88. Reilly RF, Ellison DH (2000) Mammalian distal tubule: physiology, pathophysiology, and molecular anatomy. Physiol Rev 80:277-313

89. Sapino A, Macri L, Tonda L, Bussolati G (1993) Oxytocin enhances myoepithelial cell differentiation and proliferation in the mouse mammary gland. Endocrinology 133:838-842 
90. Schwartz GJ, Al-Awqati Q (2005) Role of hensin in mediating the adaptation of the cortical collecting duct to metabolic acidosis. Curr Opin Nephrol Hypertens 14:383-388

91. Shen WP, Horng JL, Lin LY (2011) Functional plasticity of mitochondrion-rich cells in the skin of euryhaline medaka larvae (Oryzias latipes) subjected to salinity changes. Am J Physiol Regul Integr Comp Physiol 300:R858-R868

92. Shih TH, Horng JL, Hwang PP, Lin LY (2008) Ammonia excretion by the skin of zebrafish (Danio rerio) larvae. Am J Physiol Cell Physiol 295:C1625-C1632

93. Shih TH, Horng JL, Liu ST, Hwang PP, Lin LY (2012) Rhcg1 and NHE3b are involved in ammonium-dependent sodium uptake by zebrafish larvae acclimated to low-sodium water. Am J Physiol Regul Integr Comp Physiol 302:R84-R93

94. Shimizu T, Yoshitomi K, Nakamura M, Imai M (1990) Effects of PTH, calcitonin, and cAMP on calcium transport in rabbit distal nephron segments. Am J Physiol Renal Fluid Electrolyte Physiol 259:F408-F414

95. Shmukler BE, Clark JS, Hsu A, Vandorpe DH, Stewart AK, Kurschat CE, Choe SK, Zhou Y, Amigo J, Paw BH, Alper SL (2008) Zebrafish ae2.2 encodes a second slc4a2 anion exchanger. Am J Physiol Regul Integr Comp Physiol 294:R1081-R1091

96. Shmukler BE, Kurschat CE, Ackermann GE, Jiang L, Zhou Y, Barut B, Stuart-Tilley AK, Zhao J, Zon LI, Drummond IA, Vandorpe DH, Paw BH, Alper SL (2005) Zebrafish slc4a2/ae2 anion exchanger: cDNA cloning, mapping, functional characterization, and localization. Am J Physiol Renal Physiol 289:F835-F849

97. Shono T, Kurokawa D, Miyake T, Okabe M (2011) Acquisition of glial cells missing 2 enhancers contributes to a diversity of ionocytes in zebrafish. PLoS One 6:e23746

98. Skelton LA, Boron WF, Zhou Y (2010) Acid-base transport by the renal proximal tubule. J Nephrol 23:S4-S18

99. Song HK, Kim WY, Lee HW, Park EY, Han KH, Nielsen S, Madsen KM, Kim J (2007) Origin and fate of pendrin-positive intercalated cells in developing mouse kidney. J Am Soc Nephrol 18:2672-2682

100. Sussman CR, Zhao J, Plata C, Lu J, Daly C, Angle N, DiPiero J, Drummond IA, Liang JO, Boron WF, Romero MF, Chang MH (2009) Cloning, localization, and functional expression of the electrogenic $\mathrm{Na}^{+}$bicarbonate cotransporter (NBCe1) from zebrafish. Am J Physiol Cell Physiol 297:C865-C875

101. Tamma R, Colaianni G, Zhu LL, DiBenedetto A, Greco G, Montemurro G, Patano N, Strippoli M, Vergari R, Mancini L et al (2009) Oxytocin is an anabolic bone hormone. Proc Natl Acad Sci USA 106:7149-1754

102. Tang CH, Lee TH (2011) Ion-deficient environment induces the expression of basolateral chloride channel, ClC-3-like protein, in gill mitochondrion-rich cells for chloride uptake of the tilapia Oreochromis mossambicus. Physiol Biochem Zool 84:54-67

103. Thomas W, Dooley R, Harvey BJ (2010) Aldosterone as a renal growth factor. Steroids 75:550-554

104. Tseng DY, Chou MY, Tseng YJ, Hsiao CD, Huang CJ, Kaneko T, Hwang PP (2009) Effects of stanniocalcin 1 on calcium uptake in zebrafish (Danio rerio) embryo. Am J Physiol Regul Integr Comp Physiol 296:R549-R557

105. Vanoevelen J, Janssens A, Huitema LF, Hammond CL, Metz JR, Flik G, Voets T, Schulte-Merker S (2011) Trpv5/6 is vital for epithelial calcium uptake and bone formation. FASEB J 25:3197-3207

106. Vidarsson H, Westergren R, Heglind M, Blomqvist SR, Breton S, Enerback S (2009) The forkhead transcription factor Foxil is a master regulator of vacuolar H-ATPase proton pump subunits in the inner ear, kidney and epididymis. PLoS One 4:e4471

107. Wagner CA, Devuyst O, Bourgeois S, Mohebbi N (2009) Regulated acid-base transport in the collecting duct. Pflügers Arch Eur J Physiol 458:137-156

108. Wagner GF, Guiraudon CC, Milliken C, Copp DH (1995) Immunological and biological evidence for a stanniocalcin-like hormone in human kidney. Proc Natl Acad Sci USA 92:1871-1875

109. Wagner CA, Mohebbi N, Capasso G, Geibel JP (2011) The anion exchanger pendrin (SLC26A4) and renal acid-base homeostasis. Cell Physiol Biochem 28:497-504

110. Wagner GF, Vozzolo BL, Jaworski E, Haddad M, Kline RL, Olsen HS, Rosen CA, Davidson MB, Renfro JL (1997) Human stanniocalcin inhibits renal phosphate excretion in the rat. J Bone Miner Res 12:165-171

111. Wang YF, Tseng YC, Yan JJ, Hiroi J, Hwang PP (2009) Role of SLC12A10.2, a Na-Cl cotransporter-like protein, in a $\mathrm{Cl}$ uptake mechanism in zebrafish (Danio rerio). Am J Physiol Regul Integr Comp Physiol 296:R1650-R1660

112. Warne JM, Hazon N, Rankin JC, Balment RJ (1994) A radioimmunoassay for the determination of arginine vasotocin (AVT): plasma and pituitary concentrations in fresh- and seawater fish. Gen Comp Endocrinol 96:438-444

113. Weiner ID, Verlander JW (2011) Role of $\mathrm{NH}_{3}$ and $\mathrm{NH}_{4}{ }^{+}$transporters in renal acid-base transport. Am J Physiol Renal Physiol 300:F11-F23

114. Welling PA, Ho K (2009) A comprehensive guide to the ROMK potassium channel: form and function in health and disease. Am J Physiol Renal Physiol 297:F849-F863

115. Wendelaar Bonga SE, Pang PKT (1991) Control of calcium regulating hormones in the vertebrates: parathyroid hormone, calcitonin, prolactin and stanniocalcin. Int Rev Cytol 128:139-213

116. Wright PA, Randall DJ, Perry SF (1989) Fish gill water boundary layer: a site of linkage between carbon dioxide and ammonia excretion. J Comp Physiol 158B:627-635

117. Wright PA, Wood CM (2009) A new paradigm for ammonia excretion in aquatic animals: role of rhesus $(\mathrm{Rh})$ glycoproteins. J Exp Biol 212:2303-2312

118. Wu SC, Horng JL, Liu ST, Hwang PP, Wen ZH, Lin CS, Lin LY (2010) Ammonium-dependent sodium uptake in mitochondrionrich cells of medaka (Oryzias latipes) larvae. Am J Physiol Cell Physiol 298:C237-C250

119. Yan JJ, Chou MY, Kaneko T, Hwang PP (2007) Gene expression of $\mathrm{Na}^{+} / \mathrm{H}^{+}$exchanger in zebrafish $\mathrm{H}^{+}$-ATPase-rich cells during acclimation to low- $\mathrm{Na}^{+}$and acidic environments. Am J Physiol Cell Physiol 293:C1814-C1823

120. Yemelyanov A, Czwornog J, Chebotaev D, Karseladze A, Kulevitch E, Yang X, Budunova I (2007) Tumor suppressor activity of glucocorticoid receptor in the prostate. Oncogene 26:1885-1896

121. Yoshiko Y, Aubin JE (2004) Stanniocalcin 1 as a pleiotropic factor in mammals. Peptides 25:1663-1669 